\title{
The clinical outcomes and effectiveness of mHealth interventions for diabetes and hypertension: a systematic review and meta-analysis
}

\author{
Yaqian Mao ${ }^{[1]}$, Wei Lin $^{[2]}$, Junping Weng ${ }^{[2]}$, Gang Chen ${ }^{[1] ~[2] ~}$ \\ [1] The Shengli Clinical Medical College, Fujian Medical University, Fuzhou, Fujian 350001, China. \\ [2] Department of endocrinology, Fujian Provincial Hospital, Fuzhou, Fujian 350001, China. \\ [3] Fujian Provincial Key Laboratory of Medical Analysis, Fujian Academy of Medical. Fuzhou, Fujian \\ 350001, China.
}

Correspondence to: Gang Chen, Fujian Provincial Hospital, Fuzhou 350000, China

Email: chengangfj@163.com

Tel: +86-1350933707

\section{Abstract}

Background:With the development of technology, mobile health (mHealth) intervention has been proposed as a treatment strategy for chronic diseases that could improve the quality of chronic care and outcomes in some developed countries. However, the effectiveness of mHealth intervention in developing countries is not clear.

Purpose: A systematic review and meta-analysis was conducted to study the clinical outcomes and effectiveness of mHealth interventions for diabetes and hypertension in countries with different levels of economic development.

Methods: Pubmed, ResearchGate, Embase and Cochrane documents were searched by computer, and the retrieval period was from 2008 to June 2019. All studies were randomized controlled trials (RCTs) comparing mHealth treatments to other traditional treatments. Meta-analysis was conducted using stata software.

Results: 51 RCTs (N=13,054 participants) were eligible for this systematic review and meta-analysis. Compared with the usual care, the mHealth interventions yielded significant mean differences in clinical outcomes, and had a positive effect on countries at different levels of economic development. It is reassuring that we found mHealth interventions combined with human intelligence could significantly improve 
clinical outcomes more than mHealth interventions alone [WMD $(95 \% \mathrm{Cl})=-6.75$ $(-9.98,-3.52)]$ VS $[\mathrm{WMD}(95 \% \mathrm{Cl})=-2.53 \quad(-4.99,-0.07)]$. The main secondary outcomes showed that mHealth interventions could also improve quality of life, satisfaction and self-efficacy, etc.

Conclusion: This review shown that mHealth interventions as a therapeutic strategy could improve the management of diabetes and hypertension in countries with different levels of economic development.

Keywords: mHealth interventions, diabetes mellitus, hypertension, clinical results, effectiveness, economic level.

\section{What is already known about this subject?}

-With the development of technology, mobile health (mHealth) intervention has been proposed as a treatment strategy for chronic diseases that could improve the quality of chronic care in some developed countries.

-Nowdays, there are many mHealth products on the market, whether these mHealth products can improve the patient's clinical results or improve the quality of life are still lack of research.

\section{What are the new findings?}

•mHealth interventions as a therapeutic strategy could improve the management of diabetes and hypertension in countries with different levels of economic development.

-mHealth interventions combined with human intelligence could significantly improve clinical outcomes more than mHealth interventions alone.

\section{How might these results change the focus of research or clinical practice?}

-mobile health (mHealth) intervention can as a treatment strategy for chronic diseases, especially in the undeveloped places.

-mHealth intervention treatments combined with special staff management (pharmacist, dietitian, specialist nurse and sports trainer) had more effective than mHealth interventions alone. 


\section{Introduction}

Diabetes mellitus (DM) and hypertension (HTN) are major modifiable risk factors for cardiac, cerebrovascular, and kidney diseases ${ }^{[1]}$, and are prevalent illnesses that co-occur in many patients. In the 2015 global risk factor assessment, high blood pressure, high blood sugar and smoking ${ }^{[2]}$ were the top three risk factors for increased disability, and sequelae caused by these factors, such as heart disease and stroke, were the leading causes of death ${ }^{[3]}$. DM and HTN are growing in epidemic proportions and disproportionately affects lower income, diverse countries. How to better manage chronic diseases has become the key to global health problems.

The prevalence of DM has been increasing worldwide in the past two decades, especially at a particularly fast pace in some developing countries, such as China and India $^{[4-7]}$. China has a large burden of diabetes, According to a 2010 national survey, $11 \%$ of adults in China had diabetes, affecting 109.6 million individuals ${ }^{[6]}$. What's more, the prevalence of HTN in China is also high and increasing. According to a study from China ${ }^{[8]}$ that $33.6 \%$ or 335.8 million of the Chinese adult population had HTN in 2010, But only $3.9 \%$ patient were controlled to the currently recommended target of BP $<140 / 90 \mathrm{mmHg}$. So develop some lower-cost and more effective methods for disease treatment and self-management are greatly needs in some less developed areas.

With the development of technology, mobile health (mHealth) management model has gradually entered the public life. More and more people have mHealth equipment, including lower socio-economic status groups ${ }^{[9-11]}$. The use of mHealth interventions may be an economical and effective method to provide disease self-management, and change the behavior of patients ${ }^{[12-14]}$, especially in patients with lower socioeconomic status.

Nowdays, there are many mHealth products on the market, whether these mHealth products can improve the patient's clinical results or improve the quality of life are still lack of research. Some early literature reviews focused on assessing the practicability in different smart medical devices or mobile applications (Apps) ${ }^{[15-18]}$ in 
the management of patients with chronic diseases, while few reviews evaluated the effectiveness of existing mHealth devices as a health tool in the management of diabetes and hypertension. Furthermore, the efficacy and applicability of mHealth intervention have been confirmed by many clinical trials in developed countries, but few RCTs performed in China and other developing countries. In order to test whether mHealth interventions can improve the clinical outcome and effectiveness in areas with different levels of economic development, we carried out the systematic review and meta-analysis.

\section{Methods}

\section{Search strategy and selection criteria}

In order to identify studies that have investigated the effectiveness of mHealth intervention in disease (DM and HTN) management, we searched PubMed, ResearchGate, Embase and Cochrane for relevant articles, published between January 2008 to June 2019, because 2008 was the first consumer-oriented mobile application launched ${ }^{[15]}$. All articles included in this study are in English.

The terms we used in the PubMed, ResearchGate, Embase, Cochrane search included "telemedicine and diabetes mellitus", "telemedicine and hypertension", "telemedicine and blood pressure,high", "telemedicine and blood pressures,high", "telemedicine and high blood pressure", "telemedicine and high blood pressures", "mobile health and diabetes mellitus", "mobile health and hypertension", "mobile health and blood pressure,high", "mobile health and blood pressures,high", "mobile health and high blood pressure", "mobile health and high blood pressures", "Health, mobile and diabetes mellitus", "Health, mobile and hypertension", "Health, mobile and blood pressure,high", "Health, mobile and blood pressures,high", "Health, mobile and high blood pressure", "Health, mobile and high blood pressures", "mHealth and diabetes mellitus", "mHealth and hypertension", "mHealth and blood pressure, high", "mHealth and blood pressures, high", "mHealth and high blood pressure", "mHealth and high blood pressures", "telehealth and diabetes mellitus", "telehealth and 
hypertension", "telehealth and blood pressure, high", "telehealth and blood pressures, high", "telehealth and high blood pressure", "telehealth and high blood pressures", "eHealth and diabetes mellitus", "eHealth and blood pressure, high", "eHealth and blood pressures, high", "eHealth and high blood pressure", "eHealth and high blood pressures", The search was limited to studies involving randomized controlled trial, humanstudies, and publication in English.

\section{Study inclusion and exclusion criteria}

Inclusion criteria that we used were, 1) Participants in studies were diabetic or/and hypertensive patient, 2) All subjects in the intervention group used mHealth intervention to conduct health management of diseases, 3) All the experimental methods were RCTs, 4) Experimental results should include observation objectives, such as the primary results (blood glucose, blood pressure), and the secondary results (self-efficacy, quality of life, satisfaction, etc.), and 5) the study was published in English.

Exclusion criteria included, 1) The full text is not available, 2) The experimental design does not meet the basic scientific requirements, 3) The study subjects were pregnant women, cancer patients and other non-target intervention groups, 4) The experimental group did not use mHealth devices for intervention or mHealth devices were not the main intervention measures, 5) The study results did not include target intervention results.

\section{Data extraction}

First, We extracted the mean and standard deviation of the clinical indicators (HbA1c, FBG, SBP, DBP) at the end of the intervention, to evaluate the difference between mHealth intervention treatment and traditional treatment. Second, we assessed the clinical outcomes (HbA1c, SBP) at countries with different levels of economic development that using the mHealth intervention, and evaluated the difference of combination therapy compare with mHealth alone. Last, we analyed the impacts of using mHealth in self-efficacy, satisfaction and healthy behaviours, etc. Two coauthors (Y. Mao, W. Lin) and a research (J. Weng) assistant extracted information from identified studies that met inclusion criteria, including study design, 
subjects, nature of the intervention, inclusion of control groups, etc. and key research results. Extracted information was reviewed by other coauthors to verify accuracy.

\section{Statistical analysis}

The methodological quality of the selected studies was assessed by using the Jadad scale $^{[19]}$, which has been recognized as a useful tool for evaluation of RCT quality ${ }^{[20]}$. Jadad scores range from 0 (very poor) to 5 (rigorous)[21].

We used Stata sofeware for all statistical analyses. Heterogeneity among studies was measured with the $I^{2}$, the magnitude of heterogeneity was divided into low $\left(I^{2}<\right.$ $25 \%)$, moderate $\left(I^{\geq} \geq 50 \%\right)$, significant $\left(I^{\geq} \geq 75 \%\right)$. When there was no significant heterogeneity in the study $\left(I^{2}<50 \%\right)$, we use a fixed-effect model to pool the data. When heterogeneity was more than moderate in the study ( $\left.I^{2} \geq 50 \%\right)$, we use a random-effects model. Mean differences (MDs) and corresponding 95\% CIs were calculated when studies had the same units or used same measurements. A sensitivity analysis was performed to examine the cause of heterogeneity.

We assessed the possibility of publication bias by constructing a funnel plot. We assessed funnel plot asymmetry using Begg and Egger tests, and defined significant publication bias as a $p$ value $<0 \cdot 1$, the Begg and Egger checks are completed with the metabias command. The trim-and-fill analysis was used to estimate the effect of publication bias on the interpretation of the results, which was completed by the metatrim command.

\section{Results}

\section{Main characteristics of the studies}

We identified 1747 studies, of which 51 (with data for participants) were included in our analysis (See Figure 1), a total of 13,054 subjects were represented in the studies.

Table 1 and Table 2 shown the main characteristics of the 51 selected studies. Of these, 36 studies (70.59\%) were conducted in developed countries, 15 studies (29.41\%) were conducted in developing countries. All of the above study were RCTs. 
The study period ranged from 2008 to 2019 , and the total sample size of the selected studies varied from 34 to 1,665 subjects. Each study included both male and female subjects. Intervention durations ranged widely from only 1 month to 5 years, most studies $(23,45.1 \%)$ had an intervention time between 3 and 6 months, 11 studies $(21.6 \%) \leq 3$ months, 17 studies $(33.3 \%)>6$ months.

Among the 51 included RCTs, Five major mHealth intervention types were involved, including, 1) mobile phone text massage (MPTM), 2) mobile phone calls (MPCs), 3) wearable or portable monitoring devices (WPMDs) ${ }^{[5]}$, 4) mobile health applications (mHealth APPs), 5) Telemedicine. The categories follow the principle of simplicity, the ease of intervention, and the degree of public understanding (refer to

\section{Appendix -Table 1)}

\section{The primary outcome of intervention}

\section{HbA1c}

Forty studies representing 8006 participants reported data on $\mathrm{HbAlc}$, and were pooled for a meta-analysis using the random-effects model. The results showed there were significant mean differences in favour of mHealth interventions compared with traditional treatments for $\mathrm{HbA1c}$ control [WMD $(95 \% \mathrm{Cl})=-0.39 \quad(-0.50,-0.29)]$

(Figure 2 HbA1c-A), however, the results demonstrated moderate heterogeneity $\left(I^{2}\right.$ $=62.7 \%, P=0.000)$, so sensitivity analysis by eliminating one study at a time was conducted (Figure 3 HbA1c-A). The mHealth interventions had positive impacts in both developed countries $[\mathrm{WMD}(95 \% \mathrm{Cl})=-0.35(-0.46,-0.24)]$ and developing countries [WMD $(95 \% \mathrm{Cl})=-0.52(-0.78,-0.26)]$ (Figure 2 HbA1c-B). Furthermore, the subgroup analysis showed that mHealth interventions had a positive effect on all types of diabetes in HbA1c control, and were more significantly in people with T2DM [WMD $(95 \% \mathrm{Cl})=-0.40(-0.52,-0.28)]$ than people with T1DM [WMD $(95 \% \mathrm{Cl})=-0.30$ 
In this analysis, there was publication bias on Egger test $(p=0 \cdot 036)$. then, further analysis with trim-and-fill test indicated that the estimates were not affected by publication bias (ie, no trimming performed because data unchanged). 
Table 1 Summary of characteristics of 51 studies that examined mHealth interventions for hypertension and diabetes treatment and management ${ }^{1}$

\begin{tabular}{|c|c|c|c|c|c|c|c|c|c|c|c|c|c|c|c|c|c|}
\hline $\mathbf{D}^{2}$ & Reference & SS & $\begin{array}{l}\text { Gender } \\
\text { (female) }\end{array}$ & $\operatorname{Age}(y)^{3}$ & $\begin{array}{c}\text { mHealth } \\
\text { type }\end{array}$ & ID $^{2}$ & Reference & SS & $\begin{array}{l}\text { Gender } \\
\text { (female) }\end{array}$ & $\operatorname{Age}(\mathbf{y})^{3}$ & $\begin{array}{c}\text { mHealth } \\
\text { type }\end{array}$ & $\mathrm{ID}^{2}$ & Reference & SS & $\begin{array}{l}\text { Gender } \\
\text { (female) }\end{array}$ & $\operatorname{Age}(y)^{3}$ & 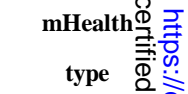 \\
\hline 1 & $\begin{array}{c}\text { Goodarzi, } \\
\mathrm{M}^{[22]}\end{array}$ & 81 & $\begin{array}{c}63 \\
(77.78 \%)\end{array}$ & $\begin{array}{l}\text { Exp:50.98(10.32), } \\
\text { Cont:56.71(9.77) }\end{array}$ & MPTM & 12 & $\begin{array}{c}\text { Kleinman, } \mathrm{N} . \\
\mathrm{J}^{[23]}\end{array}$ & 90 & $\begin{array}{c}27 \\
(30 \%)\end{array}$ & $\begin{array}{l}\text { Exp:48.8(9.0), } \\
\text { Cont:48.0(9.5) }\end{array}$ & mHealth Apps & 23 & Di, Bartolo P & 182 & $\begin{array}{c}89 \\
(48.90 \%)\end{array}$ & $\begin{array}{l}\text { Exp:17.6(3.1), } \\
\text { Cont:17.8(3.0) }\end{array}$ & $\begin{array}{r}\text { mHealth Apps } \\
\text { +WPMD疋 } \\
\text { + }\end{array}$ \\
\hline 2 & Yaron, $\mathrm{M}^{[25]}$ & 67 & $\begin{array}{c}35 \\
(52.24 \%)\end{array}$ & $\begin{array}{l}\text { Exp:43(11), } \\
\text { Cont:45(14) }\end{array}$ & Telemedicine & 13 & $\begin{array}{c}\text { Fortmann, A. } \\
\text { L }^{[26]}\end{array}$ & 126 & $\begin{array}{c}94 \\
(74.60 \%)\end{array}$ & $\begin{array}{l}\text { Exp:47.8(9.0), } \\
\text { Cont:49.1(10.6) }\end{array}$ & MPTM & 24 & $\begin{array}{c}\text { Benson, G. } \\
\mathrm{A}^{[27]}\end{array}$ & 118 & $\begin{array}{c}53 \\
(44.92 \%)\end{array}$ & $\begin{array}{c}\text { Exp:59.8(10.2), } \\
\text { Cont:60(8.66) }\end{array}$ & 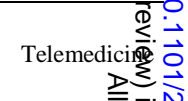 \\
\hline 3 & Ramadas, $\mathrm{A}^{[28]}$ & 128 & $\begin{array}{c}51 \\
(39.84 \%)\end{array}$ & $\begin{array}{l}\text { Exp:49.6(10.7), } \\
\text { Cont:51.5(10.3) }\end{array}$ & Telemedicine & 14 & Jeong, J. Y Y ${ }^{[29]}$ & 225 & $\begin{array}{c}72 \\
(32 \%)\end{array}$ & $\begin{array}{l}\text { Exp:52.46(8.48), } \\
\text { Cont:53.16(9.06) }\end{array}$ & Telemedicine & 25 & Boaz, $\mathrm{M}^{[30]}$ & 35 & $\begin{array}{c}22 \\
(62.86 \%)\end{array}$ & $\begin{array}{l}\text { Exp:63(10), } \\
\text { Cont:63(15) }\end{array}$ & 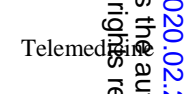 \\
\hline 4 & Abaza, $\mathrm{H}^{[31]}$ & 73 & $\begin{array}{c}41 \\
(56.16 \%)\end{array}$ & $\begin{array}{l}\text { Exp:51.24(8.66), } \\
\text { Cont:51.77(9.68) }\end{array}$ & MPTM & 15 & Kempf, K ${ }^{[32]}$ & 167 & $\begin{array}{c}77 \\
(46.11 \%)\end{array}$ & $\begin{array}{l}\text { Exp:59.0(9.0), } \\
\text { Cont:60.0(8.0) }\end{array}$ & Telemedicine & 26 & Liou, J. K ${ }^{[33]}$ & 95 & $\begin{array}{c}47 \\
(49.47 \%)\end{array}$ & $\begin{array}{l}\text { Exp:56.6(7.7), } \\
\text { Cont:57.0(7.5) }\end{array}$ & Telemed \\
\hline 5 & Wild, S. $\mathrm{H}^{[34]}$ & 321 & $\begin{array}{c}107 \\
(33.33 \%)\end{array}$ & $\begin{array}{l}\text { Exp:60.5(9.8), } \\
\text { Cont:61.4(9.8) }\end{array}$ & Telemedicine & 16 & $\begin{array}{c}\text { Nicolucci, } \\
\mathrm{A}^{[35]}\end{array}$ & 302 & $\begin{array}{c}116 \\
(38.41 \%)\end{array}$ & $\begin{array}{l}\text { Exp:59.1(10.3), } \\
\text { Cont:57.8(8.9) }\end{array}$ & Telemedicine & 27 & $\begin{array}{l}\text { Rossi, M. C. } \\
\mathrm{E}^{[36]}\end{array}$ & 130 & $\begin{array}{c}74 \\
(56.92 \%)\end{array}$ & $\begin{array}{l}\text { Exp:35.4(9.5), } \\
\text { Cont:36.1(9.4) }\end{array}$ & 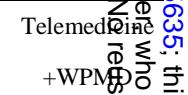 \\
\hline 6 & Duruturk, $\mathrm{N}^{[37]}$ & 44 & $\begin{array}{c}18 \\
(36 \%)\end{array}$ & $\begin{array}{l}\text { Exp:52.82(11.86), } \\
\text { Cont:53.04(10.45) }\end{array}$ & Telemedicine & 17 & $\begin{array}{l}\text { Wakefield, B. } \\
\qquad \mathbf{J}^{[38]}\end{array}$ & 108 & $\begin{array}{c}60 \\
(55.56 \%)\end{array}$ & $\begin{array}{l}\text { Exp:57.7(10.8), } \\
\text { Cont:62.5(10.9) }\end{array}$ & Telemedicine & 28 & Davis, R. M ${ }^{[39]}$ & 165 & $\begin{array}{c}123 \\
(74.55 \%)\end{array}$ & $\begin{array}{l}\text { Exp:59.9(9.4), } \\
\text { Cont:59.2(9.3) }\end{array}$ & 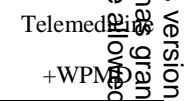 \\
\hline 7 & Sarayani, $A^{[40]}$ & 100 & $\begin{array}{c}41 \\
(41 \%)\end{array}$ & $\begin{array}{l}\text { Exp:53.4(10.3), } \\
\text { Cont:56.7(11.5) }\end{array}$ & MPCs & 18 & Chamany, $S^{[4]]}$ & 941 & $\begin{array}{c}599 \\
(63.66 \%)\end{array}$ & $\begin{array}{l}\text { Exp:56.7(11.3), } \\
\text { Cont:56.0(12.0) }\end{array}$ & MPCs & 29 & Shea, $S^{[42]}$ & 1665 & $\begin{array}{c}1046 \\
(62.82 \%)\end{array}$ & $\begin{array}{l}\text { Exp:70.8(6.5), } \\
\text { Cont:70.9(6.8) }\end{array}$ & 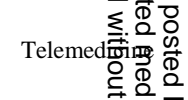 \\
\hline 8 & Wang, $\mathrm{G}^{[43]}$ & 212 & $\begin{array}{c}104 \\
(49.06 \%)\end{array}$ & $\begin{array}{l}\text { Exp:52.6(9.1), } \\
\text { Cont:54.7(10.3) }\end{array}$ & Telemedicine & 19 & Basudev, $\mathrm{N}^{[44]}$ & 208 & $\begin{array}{c}88 \\
(42.31 \%) \\
\end{array}$ & $\begin{array}{l}\text { Exp:60.5(12.3), } \\
\text { Cont:59.3(12.0) }\end{array}$ & Telemedicine & 30 & Kirwan, $M^{[45]}$ & 72 & $\begin{array}{c}44 \\
(61.11 \%) \\
\end{array}$ & $\begin{array}{l}\text { Exp:35.97(10.7) } \\
\text { Cont:34.42(10.3) }\end{array}$ & 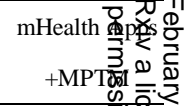 \\
\hline 9 & Kim, H. S $\mathrm{S}^{[46]}$ & 182 & $\begin{array}{c}94 \\
(51.65 \%)\end{array}$ & $\begin{array}{l}\text { Exp:52.5(9.1), } \\
\text { Cont:55.6(10.0) }\end{array}$ & Telemedicine & 20 & $\begin{array}{c}\text { Crowley, } \mathrm{Mj} \\
{[47]}\end{array}$ & 50 & $\begin{array}{c}2 \\
(4 \%)\end{array}$ & $\begin{array}{l}\text { Exp:60(8.4), } \\
\text { Cont:60(9.2) }\end{array}$ & MPCs & 31 & Moattari, $\mathrm{M}^{[48]}$ & 48 & $\begin{array}{c}27 \\
(57 \%)\end{array}$ & $18-39$ & 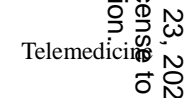 \\
\hline 10 & $\operatorname{Lim}, S^{[49]}$ & 100 & $\begin{array}{c}25 \\
(25 \%)\end{array}$ & $\begin{array}{l}\text { Exp:64.3(5.2), } \\
\text { Cont:65.8(4.7) }\end{array}$ & Telemedicine & 21 & $\begin{array}{l}\text { Odnoletkova, } \\
I^{[50]}\end{array}$ & 574 & $\begin{array}{c}221 \\
(38.50 \%)\end{array}$ & $\begin{array}{l}\text { Exp:63.8(8.7), } \\
\text { Cont:62.4(8.9) }\end{array}$ & Telemedicine & 32 & Rossi, Mc ${ }^{[51]}$ & 127 & $\begin{array}{c}67 \\
(52.76 \%)\end{array}$ & $\begin{array}{l}\text { Exp:38.4(10.3), } \\
\text { Cont:34.3(10.0) }\end{array}$ & $\begin{array}{l}\text { mHealth Apgs } \\
\text { +Telemedickse }\end{array}$ \\
\hline 11 & Cho, J. H ${ }^{[52]}$ & 484 & $\begin{array}{c}177 \\
(36.57 \%)\end{array}$ & $\begin{array}{l}\text { Exp:52.9(9.2), } \\
\text { Cont:53.4(8.7) }\end{array}$ & Telemedicine & 22 & Baron, J. ${ }^{[53]}$ & 81 & $\begin{array}{c}35 \\
(43.21 \%)\end{array}$ & $\begin{array}{l}\text { Exp:58.2(13.6), } \\
\text { Cont:55.8(13.8) }\end{array}$ & Telemedicine & 33 & Zhou, $\mathrm{P}^{[54]}$ & 114 & $\longleftarrow^{4}$ & $18-75$ & 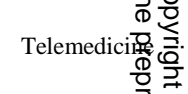 \\
\hline
\end{tabular}




\begin{tabular}{|c|c|c|c|c|c|c|c|c|c|c|c|c|c|c|c|c|c|}
\hline 34 & Tang, P. C. ${ }^{[55]}$ & 415 & $\begin{array}{c}166 \\
(40 \%)\end{array}$ & $\begin{array}{c}\text { Exp:54(10.7), } \\
\text { Cont:53.5(10.2) }\end{array}$ & Telemedicine & 40 & Kim, S. I ${ }^{[56]}$ & 34 & $\begin{array}{c}18 \\
(52.94 \%)\end{array}$ & $\begin{array}{l}\text { Exp:45.5(9.1), } \\
\text { Cont:48.5(8.0) }\end{array}$ & $\begin{array}{c}\text { Telemedicine } \\
\text { +WPTM }\end{array}$ & 46 & Green, B. B ${ }^{[57]}$ & 519 & $\begin{array}{c}287 \\
(55.30 \%)\end{array}$ & $\begin{array}{l}\text { Exp:59.3(8.6), } \\
\text { Cont:58.6(8.5) }\end{array}$ & 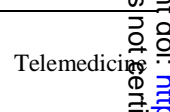 \\
\hline 35 & Piette, J. ${ }^{[58]}$ & 291 & $\begin{array}{c}150 \\
(51.5 \%)\end{array}$ & $\begin{array}{l}\text { Exp:55.1(9.4), } \\
\text { Cont:56.0(10.9) }\end{array}$ & $\begin{array}{c}\text { MPCs } \\
+ \text { WPMD }\end{array}$ & 41 & Piette, J. $\mathrm{D}^{[59]}$ & 181 & $\begin{array}{c}122 \\
(67.40 \%)\end{array}$ & $\begin{array}{l}\text { Exp:58.0(12.26), } \\
\text { Cont:57.1(10.55) }\end{array}$ & Telemedicine & 47 & $\begin{array}{c}\text { McManus, } R . \\
\mathrm{J}^{[60]}\end{array}$ & 527 & $\begin{array}{c}255 \\
(53.13 \%)\end{array}$ & $\begin{array}{l}\text { Exp:66.6 (8.8), } \\
\text { Cont:66.2 (8.8) }\end{array}$ & Telemediciy \\
\hline 36 & Cho, J. $\mathrm{H}^{[61]}$ & 71 & $\begin{array}{c}43 \\
(60.56 \%) \\
\end{array}$ & $\begin{array}{c}\text { Exp:65.3(9.3), } \\
\text { Cont:63.1(10.3) }\end{array}$ & $\begin{array}{c}\text { Telemedicine } \\
\text { +WPMD }\end{array}$ & 42 & Bobrow, $\mathrm{K}^{[62]}$ & 915 & $\begin{array}{c}662 \\
(72.35 \%) \\
\end{array}$ & $\begin{array}{l}\text { Exp:54.2(11.6), } \\
\text { Cont:54.7(11.6) }\end{array}$ & MPTM & 48 & Rifkin, D. $E^{[63]}$ & 43 & $\begin{array}{c}2 \\
(4.65 \%) \\
\end{array}$ & $\begin{array}{l}\text { Exp:68.5(7.5), } \\
\text { Cont:67.9(8.4) }\end{array}$ & $\begin{array}{r}\text { Telemedicin } \\
+ \text { WPMD }\end{array}$ \\
\hline 37 & $\begin{array}{c}\text { Bujnowska-Fe } \\
\text { dak, } \mathrm{Mm}^{[64]}\end{array}$ & 95 & $\begin{array}{c}44(46.32 \\
\%) \\
\end{array}$ & $\begin{array}{l}\text { Exp:53.1(25.2), } \\
\text { Cont:57.5(27.4) }\end{array}$ & Telemedicine & 43 & Kim, Y. $\mathrm{N}^{[65]}$ & 250 & $\begin{array}{r}100 \\
(40 \%) \\
\end{array}$ & $\begin{array}{c}\text { Exp:56.1(11), } \\
\text { Cont:58.8(10.6) }\end{array}$ & Telemedicine & 49 & Lee, $\mathrm{P}^{[66]}$ & 382 & $\begin{array}{c}192 \\
(50.26 \%) \\
\end{array}$ & $\begin{array}{l}\text { Exp:57.29(10.90) } \\
\text { Cont:58.90(10.7) }\end{array}$ & 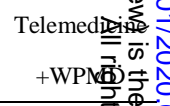 \\
\hline 38 & $\begin{array}{c}\text { Berndt, R-D } \\
\text { [67] }\end{array}$ & 68 & $\begin{array}{c}27 \\
(39.71 \%)\end{array}$ & $\begin{array}{l}\text { Exp:12.9(2.0), } \\
\text { Cont:13.2(2.9) }\end{array}$ & $\begin{array}{l}\text { mHealth Apps } \\
+ \text { Telemedicine }\end{array}$ & 44 & $\begin{array}{c}\text { McManus, R. } \\
J^{[68]}\end{array}$ & 782 & $\begin{array}{c}364 \\
(46.55 \%)\end{array}$ & $\begin{array}{l}\text { Exp:67.0(9.3), } \\
\text { Cont:66.8(9.4) }\end{array}$ & Telemedicine & 50 & Kim, J. Y Y & 95 & $\begin{array}{c}65 \\
(68.42 \%)\end{array}$ & $\begin{array}{l}\text { Exp:57.5(8.6), } \\
\text { Cont:57.7(8.7) }\end{array}$ & 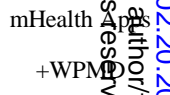 \\
\hline 39 & $\begin{array}{c}\text { Charpentier, } \\
\mathrm{G}^{[70]}\end{array}$ & 120 & $\begin{array}{c}77 \\
(64.17 \%)\end{array}$ & $\begin{array}{l}\text { Exp:31.6(12.5), } \\
\text { Cont:36.8(14.1) }\end{array}$ & $\begin{array}{l}\text { mHealth Apps } \\
+ \text { Telemedicine }\end{array}$ & 45 & $\begin{array}{c}\text { Margolis, K. } \\
L^{[71]}\end{array}$ & 450 & $\begin{array}{c}201 \\
(44.67 \%)\end{array}$ & $\begin{array}{l}\text { Exp:62.0(11.7), } \\
\text { Cont:60.2(12.2) }\end{array}$ & Telemedicine & 51 & $\begin{array}{c}\text { McKinstry, } \\
B^{[72]}\end{array}$ & 401 & $\begin{array}{c}164 \\
(40.90 \%)\end{array}$ & $\begin{array}{l}\text { Exp:60.5(11.8), } \\
\text { Cont:60.8(10.7) }\end{array}$ & Telemedigi \\
\hline
\end{tabular}

${ }^{1} \mathrm{ID}$, identifier; mHealth, using of telemedicine, mobile phone, applications and wireless technologies for improving the health care processes and clinical outcomes; mHealth Apps, mobile

health applications; MPTM, mobile phone text messages; MPCs, mobile phone calls; WPMD, wearable or portable monitoring device; SS : sample size

${ }^{2}$ Study IDs indicate the 1 st to 51 th study.

${ }^{3}$ Unless otherwise indicated, values are ranges or means \pm SDs; Exp, experimental group; Cont, control group.

${ }^{4}$ Not mentioned in the study 
medRxiv preprint doi: https://doi.org/10.1101/2020.02.20.20025635; this version posted February 23, 2020. The copyright holder for this preprint (which was not certified by peer review) is the author/funder, who has granted medRxiv a license to display the preprint in perpetuity.

All rights reserved. No reuse allowed without permission.

Table 2 Summary of characteristics of 51 studies that examined mHealth interventions ${ }^{1}$ for hypertension and diabetes treatment and management

\begin{tabular}{|c|c|c|}
\hline Category & Number of studies(n, \%) & Study ID $^{2}$ \\
\hline \multicolumn{3}{|l|}{ Country/setting } \\
\hline \multicolumn{3}{|l|}{ Developed country } \\
\hline Unite state & $13(25.5 \%)$ & $\begin{array}{l}13,17,18,20,24,28,29,34,35,45 \\
46,48,50\end{array}$ \\
\hline England & $6(11.8 \%)$ & $5,19,22,44,47,51$ \\
\hline Korea & $6(11.8 \%)$ & $10,11,14,36,40,43$ \\
\hline Italy & $4(7.8 \%)$ & $16,23,27,32$ \\
\hline Germany & $2(3.9 \%)$ & 15,38 \\
\hline Israel & $2(3.9 \%)$ & 2,25 \\
\hline Australia & $1(2.0 \%)$ & 30 \\
\hline Belgium & $1(2.0 \%)$ & 26 \\
\hline France & $1(2.0 \%)$ & 44 \\
\hline \multicolumn{3}{|l|}{ Developing country } \\
\hline China & $5(9.8 \%)$ & $8,9,26,33,49$ \\
\hline Iran & $3(5.9 \%)$ & $1,7,31$ \\
\hline Egypt & $1(2.0 \%)$ & 4 \\
\hline India & $1(2.0 \%)$ & 12 \\
\hline Honduras and Mexico & $1(2.0 \%)$ & 41 \\
\hline Malaysia & $1(2.0 \%)$ & 3 \\
\hline Turkey & $1(2.0 \%)$ & 6 \\
\hline Poland & $1(2.0 \%)$ & 37 \\
\hline South Africa & $1(2.0 \%)$ & 42 \\
\hline \multicolumn{3}{|l|}{ Intervention time/duration } \\
\hline$\leq 3 \mathrm{mo}$ & $11(21.6 \%)$ & $1,4,6,7,15,17,31,33,36,38,41$ \\
\hline $3-6 \mathrm{mo}$ & $23(45.1 \%)$ & $\begin{array}{l}3,8-14,20,21,23,25,26,27,30 \\
32,3739,43,48-51\end{array}$ \\
\hline$>6 \mathrm{mo}$ & $17(33.3 \%)$ & $\begin{array}{l}2,5,16,18,19,22,24,28,29,34, \\
35,40,42,44-47\end{array}$ \\
\hline \multicolumn{3}{|l|}{ Sample size } \\
\hline$<100$ & $17(33.3 \%)$ & $\begin{array}{l}1,2,4,6,12,20,22,25,26,30,31 \\
36,37,38,40,48,50\end{array}$ \\
\hline $100-500$ & $27(52.9 \%)$ & $\begin{array}{l}3,5,7-11,13-17,19,23,24,27,28 \\
32-35,39,41,43,45,49,51\end{array}$ \\
\hline$>500$ & $7(13.7 \%)$ & $18,21,29,42,44,46,47$ \\
\hline \multicolumn{3}{|l|}{ Targeted patient $\mathbf{t}^{3}$} \\
\hline T1DM & $7(13.7 \%)$ & $2,23,27,30,32,38,39$ \\
\hline $\mathrm{T} 2 \mathrm{DM}$ & $28(54.9 \%)$ & $\begin{array}{l}1,3-16,19-21,24,26,28,29,33-37 \\
40\end{array}$ \\
\hline T1DM \& T2DM combined & $4(7.8 \%)$ & $18,22,25,31$ \\
\hline
\end{tabular}




\footnotetext{
T2DM \& HTN combined 1(2.0\%) 17

HTN $11(21.6 \%) \quad 41-51$

${ }^{1}$ mHealth ${ }^{[5]}$, using of telemedicine, mobile phone, applications and wireless technologies for improving the health care processes and clinical outcomes; MPTM, mobile phone text messages; MPCs, mobile phone calls; mHealth Apps, mobile health applications, WPMD, wearable or portable monitoring device, Telemedicine, distance therapy, management, education, rehabilitation, monitoring, and follow-up, etc

${ }^{2}$ Study ID, the related references for each study.

${ }^{3} \mathrm{~T} 1 \mathrm{DM}$, type 1 diabetes mellitus; T2DM, type 2 diabetes mellitus; HTN, hypertension
}

\section{FBG}

In a pooled analysis of 15 trials using the random-effects model, the mHealth interventions led to a mean greater reduction in FBG [WMD $(95 \% \mathrm{CI})=-0.52(-0.93$, -0.12)] (Figure 2 FBG-D) than with any other traditional treatment strategy. The results demonstrated moderate heterogeneity $\left(I^{2}=57.6 \%, P=0.003\right)$. A sensitivity analysis was conducted (Figure 3 FBG-B). In this analysis, no publication bias was evident $(p=0 \cdot 16)$.

\section{SBP}

In a pooled analysis of 30 trials representing 9476 participants (HTN and DM) reported data on SBP, the mHealth intervention led to a mean higher reduction in SBP [WMD $(95 \% \mathrm{CI})=-2.99(-4.19,-1.80)]$ (Figure 4 SBP-A) than with any other traditional treatment. But the results demonstrated considerable heterogeneity $\left(I^{2}=67.3 \%, P=0.000\right)$, therefore, we conducted a sensitivity analysis. when Green et al. 2008 was excluded, the $I^{2}$ was $60.1 \%$, when Margolis et al. 2013 was excluded, the $I^{2}$ was $49.6 \%$ (Figure 3 SBP-C, D). There was no significant publication bias in this analysis $(p=0 \cdot 439)$. we conducted a subgroup analysis in countries of different economic levels using mHealth interventions, 11 studies representing 4189 hypertensive patients reported data on SBP, and were pooled for a meta-analysis using the random-effects model. The results showed positive outcomes in favour of mHealth intervention in developed countries [WMD $(95 \% \mathrm{Cl})=-5.72(-7.46,-3.99)]$, but no significant difference in developing countries [WMD $(95 \% \mathrm{Cl})=0.25(-3.10$, 3.59)]. In the study, it is reassuring that we found mHealth interventions combined with professional managements are more effective than mHealth interventions alone 
[WMD $(95 \% \mathrm{Cl})=-6.17(-8.83,-3.50)]$ VS [WMD $(95 \% \mathrm{Cl})=-2.16(-5.07,0.75)]$

\section{(Figure 4 SBP-B, C).}

\section{DBP}

In a pooled analysis of 28 trials representing 8506 participants reported data on DBP, the mHealth intervention led to a mean greater reduction in DBP [WMD (95\%CI) $=-1.14(-1.86,-0.42)$ ] (Figure 4 DBP-D) than with any other traditional treatment. Due to the moderate heterogeneity $\left(I^{2}=57.1 \%, P=0.000\right)$, we performed a sensitivity analysis, when Green et al. 2008 and Margolis et al. 2013 were excluded separately, the $I^{2}$ was $42.7 \%$ (Figure 3 DBP-E, F). In this analysis, no publication bias was evident $(p=0.857)$.

\section{The secondary results of intervention}

Most of all the studies included described positive results, showing that most patients' clinical indicators improved after using mHealth interventions. 14 studies (27.45\%) described the improvement of compliance, 13 (25.49\%) reported the improvement of self-care ability, $12(23.53 \%)$ reported the improvement of eating habits and physical exercise, 10 (19.61\%) described the change of positive lifestyle, and so on (Table 3).

Table 3 The effects of mHealth interventions on secondary outcomes related to hypertension and diabetes ${ }^{1}$.

\section{Secondary outcomes}

Study ID ${ }^{2}$

Improved knowledge (diseases, medicines, eating habits,etc.) $1,3,4$

Improved adherence (medication, monitoring, instructions, follow-up visit, etc.)

$4,5,7,8,12,14,18,23,24,25,36$,

Improved self-efficacy/self-care (individuals motivated, diabetes $38,45,49$

care, sense of treatment, attitude, etc.)

$1,3,4,7,15,18,20,35,36,37,38$,

Improved behaviour (such as physical activity levels, practical 45,50

ability, physical functioning, eating habits , medication habits, etc.) $1,3,6,10,15,16,18,24,30,35,41$, 45

\section{Improved satisfaction}

$2,11,12,13,27,32,34,38,41,45$

Improved symptoms (such as anxiety, depression, etc.)

$6,18,22,25,34,35,41$

Improved quality of life (such as health status, diabetes care, 6, 16, 21, 22, 25, 27, 32, 35, 37, 41 mental health, psychosocial status, etc.) 
Improve complications (such as cardiovasular disease risk, 14, 15, 25, 28, 32, 33 hypoglycemia risk, etc.)

Changed bad habits (such as smoking and drinking, etc.) 50 Reduced costs 2,39

1. All outcomes were measured after the intervention period and compare to the baseline data or among groups after intervention

2. See Table 1 for the related references for each study.

\section{Discussion}

This is the first systematic review and meta-analysis to compare the effects of mHealth interventions in countries with different economic development levels, and evaluate the control of clinical outcomes and benefits affter interventions. 51 studies meeting the inclusion criteria were included. Our results show that compared with traditional care treatments, mHealth interventions can yield improved clinical outcomes in HbA1c, FBG, SBP, DBP control in different levels of economic development, and had positive effects on improving quality of life, satisfaction and self-efficacy, etc.

These results enhanced the evidence on the overall effectiveness of mHealth intervention treatments in DM and HTN management as documented in previous studies $^{[15-17]}[73,74]$. Most reviews about mHealth interventions before were limited to a single type of intervention, and mainly aimed to evaluate the effect of intervention time and types $^{[15,16]}$, such as telemedicine ${ }^{[16][73]}$, mHealth Apps ${ }^{[15][18]}$, $\mathrm{MPTM}^{[17]}$, etc. However in our review, the mHealth interventions included five types that using in healthcare industries presently. The results we found in our data showed the beneficial effect of mHealth interventions were more pronounced among patients with T2DM than among those with T1DM, which is consistent with Dejun Su,et al's studies ${ }^{[16]}$. The main reason caused the difference of intervention results may due to the disease itself, as we know patients with T1DM were rely on insulin treatments. But for T2DM, especially in the early stage of diabetes can improve blood glucose by changing lifestyle and eating habits, which was consistent with the direction of mHealth interventions. So how to develop specific interventions for 
different types of patients are the key to achieving efficacy. Look at the figure 2, we found moderate heterogeneity in the sensitivity analysis of HbA1c, when Kim,S.I et al. 2008 was excluded, the heterogeneity decreased significantly, after checking and comparing the original studies carefully, we inferred that the heterogeneity may be due to the small sample size $(\mathrm{N}=34)$.

In our studies, an interesting findings was that the mHealth interventions compare to the control group could significantly improved SBP control in developed countries, but no significant difference in developing countries. after reading, checking and comparing the original studies carefully, we found that the three RCTs (Lee et al. 2016, Piette et al. 2012, Bobrow et al. 2016) performed in the developing countries just using mHealth treatments as intervention alone, didn't combine the human intelligence which can provide professional guidance about medication, lifestyle, behaviour, etc. But in developed countries the mHealth care usually combined with specialists and professionals to provide disease-related management during the intervention. These results enhanced the evidence on Can Hou et al's studies ${ }^{[15]}$ that health care professionals' functionality is important to achieve clinical effectiveness. To be sure, the BP outcomes in the three RCTs all have positive improvement compare to the baseline after interventions. In our study, we found moderate heterogeneity in the sensitivity analysis of SBP and DBP, when Green et al 2008, Margolis et al 2013 were excluded separately, the heterogeneity decreased significantly. After a detailed analysis of the original study, we found that both articles all had professional pharmacists involving in disease management. we inferred that professionals' interventions can strengthen management that may be the source of heterogeneity. In order to test the conjecture, we conducted a subgroup analysis to campare the combined intervention with mHealth intervention alone. the results are encouraging, mHealth intervention treatments combined with special staff management (pharmacist, dietitian, specialist nurse and sports trainer) had more effective than mHealth interventions alone [WMD $(95 \% \mathrm{Cl})=-6.17 \quad(-8.83$, $-3.50)]$ VS [WMD $(95 \% \mathrm{Cl})=-2.16(-5.07,0.75)]$, The results further validate the 
above discussion that professionals' functionality is important to achieve clinical effectiveness.

Nowdays, many reviews ${ }^{[15,16]}$ focus on analyzing the effect of mHealth interventions on chronic disease management in developed countries, but lacking the assessment in developing countries ${ }^{[5]}$. In our studies we included 15 RCTs which conducted in developing countries in recent years, aimed to assess the effectiveness of mHealth interventions in less developed countries . It is reassuring that our review found mHealth could improve the management of chronic diseases in countries with different economic levels, and emphasized that mHealth intervention combined with professionals' functionality were important to achieve clinical effectiveness.

\section{Quality of included studies}

We evaluated the quality of 51 included studies based on jaded scores, allocation sequences were randomly generated in all trials. Among them, 37 studies (72.55\%) reported the concealment of the allocation and addressed incomplete outcome data adequately. This is an open study, given the nature of the intervention, it was not possible to blind patients or their clinicians to their experimental assignment, So double blindness is not feasible. 44 studies (86.27\%) described Follow-up reporting, and descriped the reason of dropping out (Appendix-Table 2)

\section{Limitations}

Confounding factors may significantly impact our findings. For example, when we conducted the subgroup analysis by diabetes type of intervention, we did not control for potential differences in baseline HbA1c across the subgroups, futures studies need to explore the findings. However, despite the growing interest in the use of various mobile health technologies, the long-term effects of such interventions are unknown and will need to be tested in a longer and more representative population.

\section{Conclusion}


The present systematic review and meta-analysis indicates that mHealth intervention treatments can improve clinical outcomes, decrease depressive symptoms, improve the quality of life and enhance self-efficacy among patients in countries at all levels of economic development. and emphasized the importance that combined intervention is important to achieve clinical effectiveness.

Funding : None.

Conflict of interest: No conflict of interest has been declared by the authors.

Author contributions : All authors have agreed on the final version and meet at least one of the following criteria:1, Substantial contributions to design, acquisition of data or analysis and interpretation of data, 2, Drafting the article or revising it critically for important intellectual content.

Figure 1 Flow chart of the literature search and study selection procedures. mHealth, mobile health ; RCT, randomized controlled trial.

Figure 2 Meta-analyses of mHealth intervention treatments versus other traditional treatments, comparing HbA1c and FBG. Outcomes assessed are (A) change in HbAlc at the end of intervention in studies that compared mHealth treatment with traditional treatment, (B) comparing the effects of mHealth interventions on HbA1c control in Countries with different levels of economic development, (C) comparing the effects of mHealth interventions on HbA1c control in patients with different types of diabetes, and (D) change in FBG at the end of intervention that compared mHealth treatment with traditional treatment.

Figure 3 Meta-analyses of mHealth intervention treatments versus other traditional treatments, comparing SBP and DBP. Outcomes assessed are (A) 
change in SBP at the end of intervention in studies that compared mHealth treatment with traditional treatment, (B) comparing the effects of mHealth intervention on SBP control in Countries with different levels of economic development, (C) SBP in studies that compared combination treatment with mHealth treatment alone, and (D) change in DBP at the end of intervention that compared mHealth treatment with traditional treatment.

\section{Appendix}

Table 1 The definition and classification of mobile health in our studies.

\begin{tabular}{ll}
\hline Classification & Definition \\
\hline $\begin{array}{l}\text { Mobile phone text massage } \\
\text { (MPTM) }\end{array}$ & $\begin{array}{l}\text { Using mobile phone text message for chronic disease education and } \\
\text { management. }\end{array}$ \\
Mobile phone calls (MPCs) & $\begin{array}{l}\text { Using mobile phone for chronic disease education, Management and } \\
\text { follow-up monitoring. }\end{array}$
\end{tabular}

Wearable or portable Devices which can be used to collect, upload clinical data and monitor monitoring devices patients' physiological status by wireless technology, such as pedometer, (WPMDs) dynamic blood pressure and blood glucose monitor, etc.

Mobile health applications (mHealth APPs)

Telemedicine
An apps installed on smart phones or the internet which can provide health education, disease management and calculate insulin dose and food calories, etc.

The most commonly used wireless smart technology, mainly through smartphones, networks, tablet computers perform remote monitoring, rehabilitation exercise and treatment, the main forms are video, email, phone calls, text messages and so on

Table 2 Quality of included all studies

\begin{tabular}{|c|c|c|c|c|c|c|c|}
\hline $\begin{array}{c}\text { Study } \\
\text { ID }^{1}\end{array}$ & Author & Randomisation & $\begin{array}{c}\text { Description of } \\
\text { randomisation } \\
\text { methods }\end{array}$ & $\begin{array}{c}\text { Double } \\
\text { blind }\end{array}$ & $\begin{array}{c}\text { Used identical } \\
\text { placebo }\end{array}$ & $\begin{array}{c}\text { Follow-up } \\
\text { reporting }\end{array}$ & $\begin{array}{c}\text { Total } \\
\text { score }\end{array}$ \\
\hline 1 & Goodarzi, M & 1 & 1 & 0 & 0 & 1 & 3 \\
\hline 2 & Yaron, M & 1 & 0 & 0 & 0 & 1 & 2 \\
\hline 3 & Ramadas, A & 1 & 0 & 0 & 0 & 1 & 2 \\
\hline 4 & Abaza, H & 1 & 1 & 0 & 0 & 1 & 3 \\
\hline 5 & Wild, S. H & 1 & 1 & 0 & 0 & 1 & 3 \\
\hline
\end{tabular}


medRxiv preprint doi: https://doi.org/10.1101/2020.02.20.20025635; this version posted February 23, 2020. The copyright holder for this preprint (which was not certified by peer review) is the author/funder, who has granted medRxiv a license to display the preprint in perpetuity. All rights reserved. No reuse allowed without permission.

\begin{tabular}{|c|c|c|c|c|c|c|c|}
\hline 6 & Duruturk, N & 1 & 1 & 0 & 0 & 1 & 3 \\
\hline 7 & Sarayani, A & 1 & 1 & 0 & 0 & 1 & 3 \\
\hline 8 & Wang, G & 1 & 0 & 0 & 0 & 1 & 2 \\
\hline 9 & Kim, H. S & 1 & 1 & 0 & 0 & 0 & 2 \\
\hline 10 & Lim, S & 1 & 1 & 0 & 0 & 1 & 3 \\
\hline 11 & Cho, J. H & 1 & 1 & 0 & 0 & 0 & 2 \\
\hline 12 & Kleinman, N. J & 1 & 1 & 0 & 0 & 1 & 3 \\
\hline 13 & Fortmann, A. L & 1 & 1 & 0 & 0 & 1 & 3 \\
\hline 14 & Jeong, J. Y & 1 & 0 & 0 & 0 & 1 & 2 \\
\hline 15 & Kempf, K & 1 & 1 & 0 & 0 & 1 & 3 \\
\hline 16 & Nicolucci, A & 1 & 1 & 0 & 0 & 1 & 3 \\
\hline 17 & Wakefield, B. J & 1 & 1 & 0 & 0 & 1 & 3 \\
\hline 18 & Chamany, S & 1 & 1 & 0 & 0 & 1 & 3 \\
\hline 19 & Basudev, $\mathrm{N}$ & 1 & 1 & 0 & 0 & 1 & 3 \\
\hline 20 & Rossi, M. C. E & 1 & 1 & 0 & 0 & 1 & 3 \\
\hline 21 & Odnoletkova, I & 1 & 1 & 0 & 0 & 1 & 3 \\
\hline 22 & Baron, J. S & 1 & 1 & 0 & 0 & 1 & 3 \\
\hline 23 & Di, Bartolo P & 1 & 0 & 0 & 0 & 1 & 2 \\
\hline 24 & Benson, G. A & 1 & 0 & 0 & 0 & 1 & 2 \\
\hline 25 & Boaz, M & 1 & 0 & 0 & 0 & 1 & 2 \\
\hline 26 & Liou, J. K & 1 & 0 & 0 & 0 & 1 & 2 \\
\hline 27 & Rossi, M. C. E & 1 & 1 & 0 & 0 & 1 & 3 \\
\hline 28 & Davis, R. M & 1 & 0 & 0 & 0 & 0 & 1 \\
\hline 29 & Shea, S & 1 & 0 & 0 & 0 & 1 & 2 \\
\hline 30 & Kirwan, M & 1 & 1 & 0 & 0 & 1 & 3 \\
\hline 31 & Moattari, M & 1 & 1 & 0 & 0 & 1 & 3 \\
\hline 32 & Rossi, Mc & 1 & 1 & 0 & 0 & 1 & 3 \\
\hline 33 & Zhou, P & 1 & 1 & 0 & 0 & 1 & 3 \\
\hline 34 & Tang, $\mathrm{P}$ & 1 & 1 & 0 & 0 & 1 & 3 \\
\hline 35 & Piette, J. D & 1 & 1 & 0 & 0 & 0 & 2 \\
\hline 36 & Cho, J. H & 1 & 1 & 0 & 0 & 1 & 3 \\
\hline 37 & Bujnowska-Fedak, Mm & 1 & 0 & 0 & 0 & 1 & 2 \\
\hline 38 & Berndt, R-D & 1 & 0 & 0 & 0 & 0 & 2 \\
\hline 39 & Charpentier, G & 1 & 1 & 0 & 0 & 1 & 3 \\
\hline 40 & Kim, S. I & 1 & 1 & 0 & 0 & 1 & 3 \\
\hline 41 & Piette, J. D & 1 & 1 & 0 & 0 & 0 & 2 \\
\hline 42 & Bobrow, $\mathrm{K}$ & 1 & 1 & 0 & 0 & 1 & 3 \\
\hline 43 & Kim, Y. N & 1 & 1 & 0 & 0 & 1 & 3 \\
\hline 44 & McManus, R. J & 1 & 1 & 0 & 0 & 1 & 3 \\
\hline 45 & Margolis, K. L & 1 & 0 & 0 & 0 & 1 & 2 \\
\hline 46 & Green, B. B & 1 & 1 & 0 & 0 & 1 & 3 \\
\hline 47 & McManus, R. J & 1 & 1 & 0 & 0 & 1 & 3 \\
\hline 48 & Rifkin, D. E & 1 & 1 & 0 & 0 & 1 & 3 \\
\hline
\end{tabular}


medRxiv preprint doi: https://doi.org/10.1101/2020.02.20.20025635; this version posted February 23, 2020. The copyright holder for this preprint (which was not certified by peer review) is the author/funder, who has granted medRxiv a license to display the preprint in perpetuity.

All rights reserved. No reuse allowed without permission.

\begin{tabular}{|c|c|c|c|c|c|c|c|}
\hline 49 & Lee, P & 1 & 1 & 0 & 0 & 1 & 3 \\
\hline 50 & Kim, J. Y & 1 & 0 & 0 & 0 & 0 & 1 \\
\hline 51 & McKinstry, B & 1 & 1 & 0 & 0 & 1 & 3 \\
\hline
\end{tabular}

${ }^{1}$ Study IDs indicate the 1 st to 51 th study. Jadad scores range from 0 (very poor) to 5 (rigorous) and consist of points randomization (randomized $=1$ point; table of random numbers or computer-generated randomization=additional 1 point), double blindness (double blind=1 point; use masking such as identical placebo=additional 1 point), and follow-up (stating numbers of subjects withdrawn and the reasons for them in each group of a study=1 point). 


\section{References :}

[1] Frias J, Virdi N, Raja P, et al. Effectiveness of Digital Medicines to Improve Clinical Outcomes in Patients with Uncontrolled Hypertension and Type 2 Diabetes: Prospective, Open-Label, Cluster-Randomized Pilot Clinical Trial[J]. J Med Internet Res, 2017, 19(7): e246.

[2] Collaborators G B D R F. Global, regional, and national comparative risk assessment of 79 behavioural, environmental and occupational, and metabolic risks or clusters of risks, 1990-2015: a systematic analysis for the Global Burden of Disease Study 2015[J]. Lancet, 2016, 388(10053): 1659-1724.

[3] Gaziano T A. Reducing the growing burden of cardiovascular disease in the developing world[J]. Health Aff (Millwood), 2007, 26(1): 13-24.

[4] Ma R C W. Epidemiology of diabetes and diabetic complications in China[J]. Diabetologia, 2018, 61(6): 1249-1260.

[5] Wang $Y, X u e ~ H$, Huang $Y$, et al. A Systematic Review of Application and Effectiveness of mHealth Interventions for Obesity and Diabetes Treatment and Self-Management[J]. Adv Nutr, 2017, 8(3): 449-462.

[6] Yin J, Kong A P, Chan J C. Prevention and Care Programs Addressing the Growing Prevalence of Diabetes in China[J]. Curr Diab Rep, 2016, 16(12): 130.

[7] Kleinman N J, Shah A, Shah S, et al. Improved Medication Adherence and Frequency of Blood Glucose Self-Testing Using an $\mathrm{m}$-Health Platform Versus Usual Care in a Multisite Randomized Clinical Trial Among People with Type 2 Diabetes in India[J]. Telemed J E Health, 2017, 23(9): 733-740.

[8] Bundy J D, He J. Hypertension and Related Cardiovascular Disease Burden in China[J]. Ann Glob Health, 2016, 82(2): 227-233.

[9] Graetz I, Gordon N, Fung V, et al. The Digital Divide and Patient Portals: Internet Access Explained Differences in Patient Portal Use for Secure Messaging by Age, Race, and Income[J]. Med Care, 2016, 54(8): 772-779.

[10] Kruse R L, Koopman R J, Wakefield B J, et al. Internet use by primary care patients: where is the digital divide?[J]. Fam Med, 2012, 44(5): 342-347.

[11] Lopez L, Green A R, Tan-Mcgrory A, et al. Bridging the digital divide in health care: the role of health information technology in addressing racial and ethnic disparities[J]. Jt Comm J Qual Patient Saf, 2011, 37(10): 437-445.

[12] Dobson $R$, Whittaker $R$, Jiang $Y$, et al. Effectiveness of text message based, diabetes self management support programme (SMS4BG): two arm, parallel randomised controlled trial[J]. BMJ, 2018, 361: k1959.

[13] Marcolino M S, Oliveira J a Q, D'agostino $M$, et al. The Impact of mHealth Interventions: Systematic Review of Systematic Reviews[J]. JMIR Mhealth Uhealth, 2018, 6(1): e23.

[14] Park L G, Howie-Esquivel J, Chung $M$ L, et al. A text messaging intervention to promote medication adherence for patients with coronary heart disease: a randomized controlled trial[J]. Patient Educ Couns, 2014, 94(2): 261-268.

[15] Hou C, Xu Q, Diao S, et al. Mobile phone applications and self-management of diabetes: A systematic review with meta-analysis, meta-regression of 21 randomized trials and GRADE[J]. Diabetes Obes Metab, 2018, 20(8): 2009-2013.

[16] Su D, Zhou J, Kelley M S, et al. Does telemedicine improve treatment outcomes for diabetes? 
A meta-analysis of results from 55 randomized controlled trials[J]. Diabetes Research and Clinical Practice, 2016, 116: 136-148.

[17] Haider R, Sudini L, Chow C K, et al. Mobile phone text messaging in improving glycaemic control for patients with type 2 diabetes mellitus: A systematic review and meta-analysis[J]. Diabetes Res Clin Pract, 2019, 150: 27-37.

[18] Bene B A, O'connor S, Mastellos N, et al. Impact of mobile health applications on self-management in patients with type 2 diabetes mellitus: protocol of a systematic review[J]. BMJ Open, 2019, 9(6): e025714.

[19] Jadad A R, Moore R A, Carroll D, et al. Assessing the quality of reports of randomized clinical trials: is blinding necessary?[J]. Control Clin Trials, 1996, 17(1): 1-12.

[20] Olivo S A, Macedo L G, Gadotti I C, et al. Scales to assess the quality of randomized controlled trials: a systematic review[J]. Phys Ther, 2008, 88(2): 156-175.

[21] Myung S K, Ju W, Cho B, et al. Efficacy of vitamin and antioxidant supplements in prevention of cardiovascular disease: systematic review and meta-analysis of randomised controlled trials[J]. BMJ, 2013, 346: f10.

[22] Goodarzi M, Ebrahimzadeh I, Rabi A, et al. Impact of distance education via mobile phone text messaging on knowledge, attitude, practice and self efficacy of patients with type 2 diabetes mellitus in Iran[J]. J Diabetes Metab Disord, 2012, 11(1): 10.

[23] Kleinman N J, Shah A, Shah S, et al. Impact of the gather mHealth system on A1C: Primary results of a multisite randomized clinical trial among people with type 2 diabetes in India[J]. Diabetes Care, 2016, 39(10): e169-e170.

[24] Di Bartolo P, Nicolucci A, Cherubini V, et al. Young patients with type 1 diabetes poorly controlled and poorly compliant with self-monitoring of blood glucose: can technology help? Results of the i-NewTrend randomized clinical trial[J]. Acta Diabetol, 2017, 54(4): 393-402.

[25] Yaron $M$, Sher B, Sorek D, et al. A randomized controlled trial comparing a telemedicine therapeutic intervention with routine care in adults with type 1 diabetes mellitus treated by insulin pumps[J]. Acta Diabetologica, 2019, 56(6): 667-673.

[26] Fortmann A L, Gallo L C, Garcia M I, et al. Dulce digital: An mHealth SMS based intervention improves glycemic control in hispanics with type 2 diabetes[J]. Diabetes Care, 2017, 40(10): 1349-1355.

[27] Benson G A, Sidebottom A, Hayes J, et al. Impact of ENHANCED (diEtitiaNs Helping pAtieNts CarE for Diabetes) Telemedicine Randomized Controlled Trial on Diabetes Optimal Care Outcomes in Patients with Type 2 Diabetes[J]. Journal of the Academy of Nutrition and Dietetics, 2019, 119(4): 585-598.

[28] Ramadas A, Chan C K Y, Oldenburg B, et al. Randomised-controlled trial of a web-based dietary intervention for patients with type 2 diabetes: changes in health cognitions and glycemic control[J]. BMC Public Health, 2018, 18(1): 716.

[29] Jeong J Y, Jeon J H, Bae K H, et al. Smart Care Based on Telemonitoring and Telemedicine for Type 2 Diabetes Care: Multi-Center Randomized Controlled Trial[J]. Telemed J E Health, 2018, 24(8): 604-613.

[30] Boaz M, Hellman K, Wainstein J. An automated telemedicine system improves patient-reported well-being[J]. Diabetes Technology and Therapeutics, 2009, 11(3): 181-186.

[31] Abaza H, Marschollek M, Schulze M. SMS Education for the Promotion of Diabetes Self-Management in Low \& Middle Income Countries: A Randomized Controlled Trial in 
[32] Kempf K, Altpeter B, Berger J, et al. Efficacy of the telemedical lifestyle intervention program TeLiPro in advanced stages of type 2 diabetes: A randomized controlled trial[J]. Diabetes Care, 2017, 40(7): 863-871.

[33] Liou J K, Soon M S, Chen $\mathrm{C} \mathrm{H}$, et al. Shared care combined with telecare improves glycemic control of diabetic patients in a rural underserved community[J]. Telemed J E Health, 2014, 20(2): 175-178.

[34] Wild S H, Hanley J, Lewis S C, et al. Supported Telemonitoring and Glycemic Control in People with Type 2 Diabetes: The Telescot Diabetes Pragmatic Multicenter Randomized Controlled Trial[J]. PLoS Med, 2016, 13(7): e1002098.

[35] Nicolucci A, Cercone S, Chiriatti A, et al. A Randomized Trial on Home Telemonitoring for the Management of Metabolic and Cardiovascular Risk in Patients with Type 2 Diabetes[J]. Diabetes Technol Ther, 2015, 17(8): 563-570.

[36] Rossi M C E, Nicolucci A, Di Bartolo P, et al. Diabetes interactive diary: A new telemedicine system enabling flexible diet and insulin therapy while improving quality of life: An open-label, international, multicenter, randomized study[J]. Diabetes Care, 2010, 33(1): 109-115.

[37] Duruturk N, Özköslü M A. Effect of tele-rehabilitation on glucose control, exercise capacity, physical fitness, muscle strength and psychosocial status in patients with type 2 diabetes: A double blind randomized controlled trial[J]. Primary Care Diabetes, 2019.

[38] Wakefield B J, Koopman R J, Keplinger L E, et al. Effect of home telemonitoring on glycemic and blood pressure control in primary care clinic patients with diabetes[J]. Telemed J E Health, 2014, 20(3): 199-205.

[39] Davis R M, Hitch A D, Salaam M M, et al. TeleHealth improves diabetes self-management in an underserved community: diabetes TeleCare[J]. Diabetes Care, 2010, 33(8): 1712-1717.

[40] Sarayani A, Mashayekhi M, Nosrati M, et al. Efficacy of a telephone-based intervention among patients with type-2 diabetes; a randomized controlled trial in pharmacy practice[J]. International Journal of Clinical Pharmacy, 2018, 40(2): 345-353.

[41] Chamany S, Walker E A, Schechter C B, et al. Telephone Intervention to Improve Diabetes Control: A Randomized Trial in the New York City A1c Registry[J]. American Journal of Preventive Medicine, 2015, 49(6): 832-841.

[42] Shea S, Weinstock R S, Teresi J A, et al. A randomized trial comparing telemedicine case management with usual care in older, ethnically diverse, medically underserved patients with diabetes mellitus: 5 year results of the IDEATel study[J]. J Am Med Inform Assoc, 2009, 16(4): 446-456.

[43] Wang G, Zhang Z, Feng Y, et al. Telemedicine in the Management of Type 2 Diabetes Mellitus[J]. Am J Med Sci, 2017, 353(1): 1-5.

[44] Basudev N, Crosby-Nwaobi R, Thomas S, et al. A prospective randomized controlled study of a virtual clinic integrating primary and specialist care for patients with Type 2 diabetes mellitus[J]. Diabet Med, 2016, 33(6): 768-776.

[45] Kirwan M, Vandelanotte $C$, Fenning A, et al. Diabetes self-management smartphone application for adults with type 1 diabetes: randomized controlled trial[J]. J Med Internet Res, 2013, 15(11): e235.

[46] Kim H S, Sun C, Yang S J, et al. Randomized, Open-Label, Parallel Group Study to Evaluate the Effect of Internet-Based Glucose Management System on Subjects with Diabetes in China[J]. 
Telemed J E Health, 2016, 22(8): 666-674.

[47] Crowley M J, Edelman D, Mcandrew A T, et al. Practical Telemedicine for Veterans with Persistently Poor Diabetes Control: A Randomized Pilot Trial[J]. Telemed J E Health, 2016, 22(5): 376-384.

[48] Moattari $M$, Hashemi $M$, Dabbaghmanesh $M H$. The impact of electronic education on metabolic control indicators in patients with diabetes who need insulin: a randomised clinical control trial[J]. J Clin Nurs, 2013, 22(1-2): 32-38.

[49] Lim S, Kang S M, Kim K M, et al. Multifactorial intervention in diabetes care using real-time monitoring and tailored feedback in type 2 diabetes[J]. Acta Diabetol, 2016, 53(2): 189-198.

[50] Odnoletkova I, Goderis G, Nobels F, et al. Optimizing diabetes control in people with Type 2 diabetes through nurse-led telecoaching[J]. Diabetic Medicine, 2016, 33(6): 777-785.

[51] Rossi M C, Nicolucci A, Lucisano G, et al. Impact of the "diabetes interactive diary" telemedicine system on metabolic control, risk of hypoglycemia, and quality of life: $A$ randomized clinical trial in type 1 diabetes[J]. Diabetes Technology and Therapeutics, 2013, 15(8): 670-679.

[52] Cho J H, Kim H S, Yoo S H, et al. An Internet-based health gateway device for interactive communication and automatic data uploading: Clinical efficacy for type 2 diabetes in a multi-centre trial[J]. J Telemed Telecare, 2017, 23(6): 595-604.

[53] Baron J S, Hirani S P, Newman S P. Investigating the behavioural effects of a mobile-phone based home telehealth intervention in people with insulin-requiring diabetes: Results of a randomized controlled trial with patient interviews[J]. J Telemed Telecare, 2017, 23(5): 503-512.

[54] Zhou P, Xu L, Liu X, et al. Web-based telemedicine for management of type 2 diabetes through glucose uploads: a randomized controlled trial[J]. Int J Clin Exp Pathol, 2014, 7(12): 8848-8854.

[55] Tang P C, Overhage J M, Chan A S, et al. Online disease management of diabetes: engaging and motivating patients online with enhanced resources-diabetes (EMPOWER-D), a randomized controlled trial[J]. J Am Med Inform Assoc, 2013, 20(3): 526-534.

[56] Kim S I, Kim H S. Effectiveness of mobile and internet intervention in patients with obese type 2 diabetes[J]. Int J Med Inform, 2008, 77(6): 399-404.

[57] Green B B, Cook A J, Ralston J D, et al. Effectiveness of home blood pressure monitoring, Web communication, and pharmacist care on hypertension control: a randomized controlled trial[J]. Jama, 2008, 299(24): 2857-2867.

[58] Piette J D, Richardson C, Himle J, et al. A randomized trial of telephonic counseling plus walking for depressed diabetes patients[J]. Medical Care, 2011, 49(7): 641-648.

[59] Piette J D, Datwani H, Gaudioso S, et al. Hypertension management using mobile technology and home blood pressure monitoring: results of a randomized trial in two low/middle-income countries[J]. Telemed J E Health, 2012, 18(8): 613-620.

[60] Mcmanus R J, Mant J, Bray E P, et al. Telemonitoring and self-management in the control of hypertension (TASMINH2): A randomised controlled trial[J]. The Lancet, 2010, 376(9736): 163-172.

[61] Cho J H, Kwon H S, Kim H S, et al. Effects on diabetes management of a health-care provider mediated, remote coaching system via a PDA-type glucometer and the Internet[J]. J Telemed Telecare, 2011, 17(7): 365-370. 
[62] Bobrow K, Farmer A J, Springer D, et al. Mobile Phone Text Messages to Support Treatment Adherence in Adults With High Blood Pressure (SMS-Text Adherence Support [StAR]): A Single-Blind, Randomized Trial[J]. Circulation, 2016, 133(6): 592-600.

[63] Rifkin D E, Abdelmalek J A, Miracle C M, et al. Linking clinic and home: a randomized, controlled clinical effectiveness trial of real-time, wireless blood pressure monitoring for older patients with kidney disease and hypertension[J]. Blood Press Monit, 2013, 18(1): 8-15.

[64] Bujnowska-Fedak M M, Puchala E, Steciwko A. The impact of telehome care on health status and quality of life among patients with diabetes in a primary care setting in Poland[J]. Telemed J E Health, 2011, 17(3): 153-163.

[65] Kim Y N, Shin D G, Park S, et al. Randomized clinical trial to assess the effectiveness of remote patient monitoring and physician care in reducing office blood pressure[J]. Hypertens Res, 2015, 38(7): 491-497.

[66] Lee P, Liu J C, Hsieh M H, et al. Cloud-based BP system integrated with CPOE improves self-management of the hypertensive patients: A randomized controlled trial[J]. Comput Methods Programs Biomed, 2016, 132: 105-113.

[67] Berndt R D, Takenga C, Preik P, et al. Impact of information technology on the therapy of type-1 diabetes: A case study of children and adolescents in Germany[J]. Journal of Personalized Medicine, 2014, 4(2): 200-217.

[68] Mcmanus R J, Mant J, Franssen M, et al. Efficacy of self-monitored blood pressure, with or without telemonitoring, for titration of antihypertensive medication (TASMINH4): an unmasked randomised controlled trial[J]. Lancet, 2018, 391(10124):949-959.

[69] Kim J Y, Wineinger N E, Steinhub| S R. The Influence of Wireless Self-Monitoring Program on the Relationship Between Patient Activation and Health Behaviors, Medication Adherence, and Blood Pressure Levels in Hypertensive Patients: A Substudy of a Randomized Controlled Trial[J]. Journal of medical Internet research, 2016, 18(6): e116.

[70] Charpentier G, Benhamou P Y, Dardari D, et al. The Diabeo software enabling individualized insulin dose adjustments combined with telemedicine support improves $\mathrm{HbA1C}$ in poorly controlled type 1 diabetic patients: a 6-month, randomized, open-label, parallel-group, multicenter trial (TeleDiab 1 Study)[J]. Diabetes Care, 2011, 34(3): 533-539.

[71] Margolis K L, Asche S E, Bergdall A R, et al. Effect of home blood pressure telemonitoring and pharmacist management on blood pressure control a cluster randomized clinical trial[J]. JAMA - Journal of the American Medical Association, 2013, 310(1): 46-56.

[72] Mckinstry B, Hanley J, Wild S, et al. Telemonitoring based service redesign for the management of uncontrolled hypertension: multicentre randomised controlled trial[J]. BMJ, 2013, 346: f3030.

[73] Wu C, Wu Z, Yang L, et al. Evaluation of the clinical outcomes of telehealth for managing diabetes: A PRISMA-compliant meta-analysis[J]. Medicine (Baltimore), 2018, 97(43): e12962.

[74] Ma Y, Cheng H Y, Cheng L, et al. The effectiveness of electronic health interventions on blood pressure control, self-care behavioural outcomes and psychosocial well-being in patients with hypertension: A systematic review and meta-analysis[J]. International journal of nursing studies, 2019, 92: 27-46. 


\begin{tabular}{|c|c|}
\hline $\begin{array}{l}\text { Number of records identified during } \\
\text { database search, } n=1747\end{array}$ & $\begin{array}{l}\text { Search limited to RCT, mHealth. diabetes } \\
\text { or hypertension patients }\end{array}$ \\
\hline & $\begin{array}{l}\text { Number of records excluded, } n=743 \\
\text { Duplicates, } n=649 \\
\text { Studies publish before } 2008, n=94\end{array}$ \\
\hline $\begin{array}{l}\text { Number of records identified after } \\
\text { screening of title and abstract, } n=1004\end{array}$ & \multirow{7}{*}{$\begin{array}{l}\text { Number of records excluded, } \mathrm{n}=\mathbf{7 5 2} \\
\text { Review articles, } \mathrm{n}=\mathbf{2 0 5} \\
\text { Sample size }<30, \mathrm{n}=7 \\
\text { Studies only describe mHealth (Its role and } \\
\text { value), } \mathrm{n}=67 \\
\text { Studies only focus on designing new } \\
\text { technology, model or procotol, } \mathrm{n}=95 \\
\text { Studies without targeted intervention } \\
\text { subjects, } \mathrm{n}=\mathbf{2 0 4} \\
\text { Studies without targeted intervention } \\
\text { results, } \mathrm{n}=141 \\
\text { The research method does not meet the } \\
\text { requirements (Non-RCT, mhealth was used } \\
\text { as an intervention in both groups), } \mathrm{n}=\mathbf{3 3}\end{array}$} \\
\hline & \\
\hline & \\
\hline & \\
\hline$\downarrow$ & \\
\hline $\begin{array}{l}\text { Number of full-text articles assessed for } \\
\text { eligibility, } n=252\end{array}$ & \\
\hline & \\
\hline \multirow[b]{2}{*}{$\downarrow$} & Number of records excluded, $n=201$ \\
\hline & $\begin{array}{l}\text { The full text is not available, } n=98 \\
\text { Studies without targeted results, } n=103\end{array}$ \\
\hline $\begin{array}{l}\text { Number of studies included in analysis, } \\
\mathrm{n}=51\end{array}$ & \\
\hline
\end{tabular}

Figure 1 Flow chart of the literature search and study selection procedures. mHealth, mobile health; RCT, randomized controlled trial. 


\section{Study}

Goodarzi, M (2012)

Yaron, M (2018)

Ramadas, A(2018)

Abaza. $\mathrm{H}(2017)$

Duruturk, N (2018)

Sarayani, A(2018)
Wang. G(2017)

Kang, G. S (2017)

Lim, S (2018)

Cho, J. H (2017)

Fortmann, A. L (2017)

Jeong, J. Y $Y(2018)$

Kempt, $K$ (2017)

Wakefeled, B. J (2014)

Chamany. S (2015)

Crowley. Mi (2018)

Odnoletkova. I (2018)

Baron, J. S (2017)

Benson, G.A. (2019)

Boaz: $M(2009)$

Rossi, M. C. E (2010)

Davis. R. M (2010)

Shea, S (2009)

Kinvan, M (2013)

Zhou, $P$ (2014)

Tang. P. C. (2013)
Pietre. J. D (2011)

Cho. J. H (2011)

Bujnowska-Fedak, Mm (2011)

Berndt, R-D (2014)

Moartari, M (2013)

Rossi, Mo (2013)

Overall (lsquared $=62.7 \%, P=0000)$

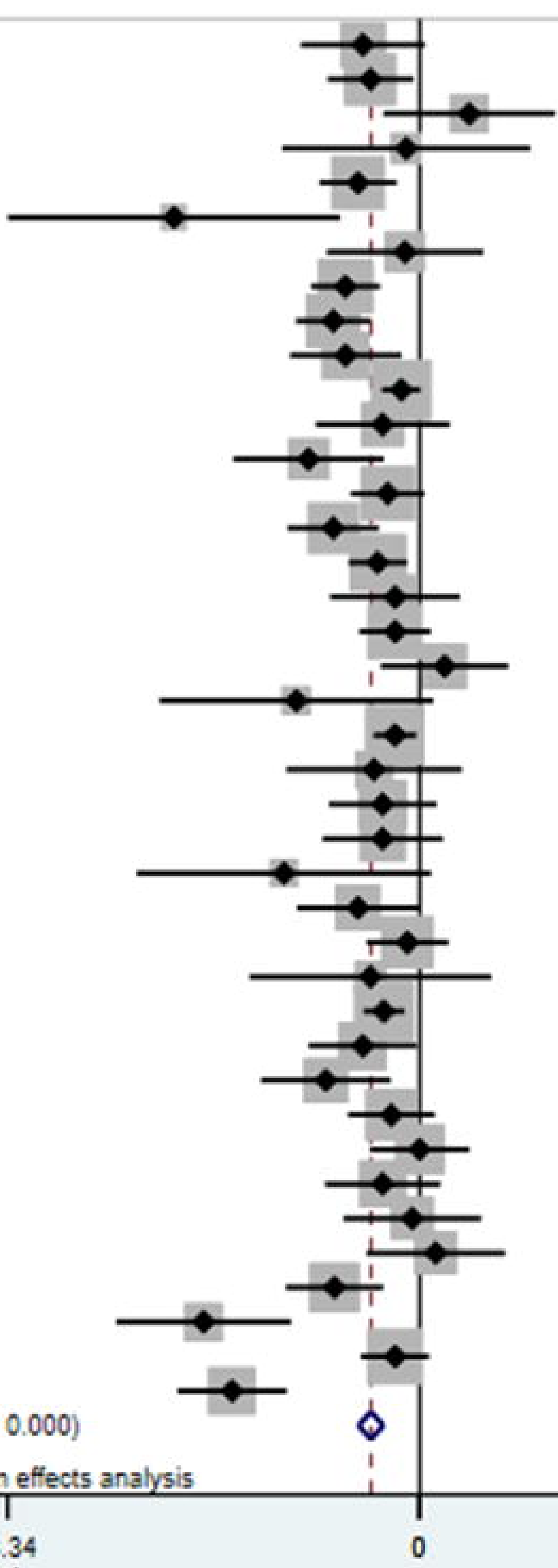

NOTE: Weights are from random effees

C

Intervention group

$\mathrm{HbA} 1 \mathrm{c}$

Study

\begin{tabular}{l} 
ID \\
medaxiv preprint doi: htt \\
\hline T2DM which was not cert \\
Goodarzi, M (2012) \\
Ramadas, A (2018)
\end{tabular}

Ramadas, A(201)
Abaza, $H(2017)$
Wod $S$ H $(2010)$

Duruturk, N (2019)

Sarayani, A (2019)
Wang. $G(2017)$

Kim, H. S (2016)

Lim. S (2016)
Cho. J. H(2017)

Kleinman, N. J (2017)
Fortmann, A. L (2017)

Jeong, J. $Y$ (2018)

Kempot, $K$ (2017)

Wakefield, B. J (2014)
Basudev, N (2016)

Crowley, Mi (2018)

Benson, G.A (2019)

Liou, J. K (2014)
Davis, R. M (2010)

Shea, $S$ (2009)

Zhou, P. (2014)
Tang, P. . . (2013)

Tang, P. . . (2013)
Piette, J. D (2011)
Cho, J. H(2011)

Bho, J. H (2011)

Kim, S. I (2008)
Subtotal (1--squared $=84.0 \%, p=0.000)$

TID

Yrom
Yaron, M (2019)
Di, Bartolo P (2017)

Rossi, M. C. E (2010)

Kirwan, $M(2013)$
Berndt $P-D$ (2014)

Charpentier, $G$ (2011)

Subtotal (l-1-squared $=31.0 \%, p=0.18$ )

T10M or T2DM

Chamany, S (2015)

Boaz, M (2009)

Mosattari, M (2013)

Subtotal (1-5quared $=82.3 \%, p=0.00$ )

Overall (l-5quared $=62.7 \%, p=0.000$ )

NOTE: Weights are from random effects analys

Intervention group
WMD $(25 \% \mathrm{Cl}) \quad \%$

$-0.46(-0.98,0.04) \quad 2.28$

$-0.40(-0.75,-0.05) \quad 3.14$

$0.40(-0.30,1.10) \quad 1.52$

$\begin{array}{ll}-0.11(-1.12,0.90) & 0.87 \\ -0.50(-0.81,-0.19) & 3.37\end{array}$

$-1.99(-3.34,-0.64) \quad 0.53$

$-0.12(-0.75,0.51) \quad 1.72$

$3.00(-0.88,-0.32) \quad 3.58$

$-0.60(-1.05,-0.15) \quad 2.53$

$\begin{array}{lll}0.15(-0.31,0.01) & 4.39\end{array}$

$0.30(-0.84,0.24) \quad 2.09$

$0.90(-1.51,-0.29) \quad 1.81$

$0.26(-0.58,0.04) \quad 3.45$

$0.70(-1.07,-0.33) \quad 3.00$

$0.34(-0.58,-0.10) \quad 3.88$

$-0.20(-0.73,0.33) \quad 2.15$

$-0.20(-0.49,0.09) \quad 3.52$

$\begin{array}{ll}0.20(-0.32,0.72) & 2.20 \\ -1.00(-2.11,0.11) & 0.74\end{array}$

$-0.20(-0.37,-0.03) \quad 4.28$

$10(-2.28,0.09) \quad 0.65$

$-0.50(-0.99,-0.01) \quad 2.31$

$-0.10(-0.43,0.23) \quad 3.24$

$-0.40(-1.38,0.58) \quad 0.91$

$\begin{array}{ll}-0.29(-0.46,-0.12) & 4.33 \\ -0.46(-0.90,-0.02) & 259\end{array}$

$\begin{array}{ll}-0.46(-0.90,-0.02) & 2.59 \\ -0.76(-1.29,-0.23) & 2.16\end{array}$

$-0.76(-1.29,-0.23) \quad 2.10$

$\begin{array}{ll}-0.23(-0.58,0.12) & 3.12 \\ 0.00(-0.40,0.40) & 2.81\end{array}$

$\begin{array}{ll}-0.30(-0.77 .0 .17) & 2.44 \\ -0.06(-0.62,0.50) & 2.02\end{array}$

$\begin{array}{ll}-0.06(-0.62,0.50) & 2.02 \\ 0.13(-0.43,0.69) & 2.00\end{array}$

$\begin{array}{ll}0.13(-0.43,0.69) & 2.00 \\ 0.69(-1.09,-0.29) & 2.85\end{array}$

$-1.75(-2.46,-1.04) \quad 1.49$

$\begin{array}{lll}-1.52(-1.96,-1.08) & 2.57\end{array}$

$-0.39(-0.50,-0.29) \quad 100.00$

3.34

Control group $\begin{array}{ll}-0.37(-1.08,0.34) & 1.48\end{array}$

$-0.30(-0.74,0.14) \quad 2.61$

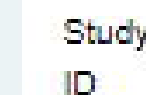

developing country

Ramadas, A (2018)

Duruturk, N (2019)

Sarayani, A (2018)
Wang. G (2017)

Kleinman, N.J (2017)

Liou. J. K (2014)
Zhou. P (2014)

Bujnowska-Fedak, Mm (2011)

Moattari, M (2013)

developed country

Yaron, M (2019)
Wild, S. H (2016)

Lim. $S$ (2016)

Cho, J. H (2017)
Fortmann, A. L (2017)

Fortmann, A. L (2017)
Jeong. J. $Y$ (2018)

Kempi, K (2017)

Wakefield, B. J (2014)
Chamany. S (2015)

Basudev, N (2016)

Crowley, Mj (2016)
Odnoletkova, I (2016)

Di, Bartolo P (2017)

Benson, G. A(2019)
Bosz, M (2009)

Rossi. M. C. E (2010)
Davis. R. M (2010)

Shea, S (2009)

Tang, P. C. (2013)

Piette, J. D (2011)

Cho, J. H (2011)

Charpentier, $G$ (2011)

Rossi, Mc (2013)

Subtotal (1-5quared $=57.9 \%, p=0.000)$

Overall (1-squared $=62.7 \%, p=0.000$ )

NOTE: Weights are from random effects anal

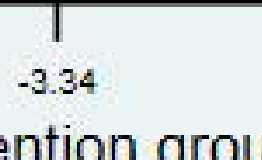

D

Intervention group

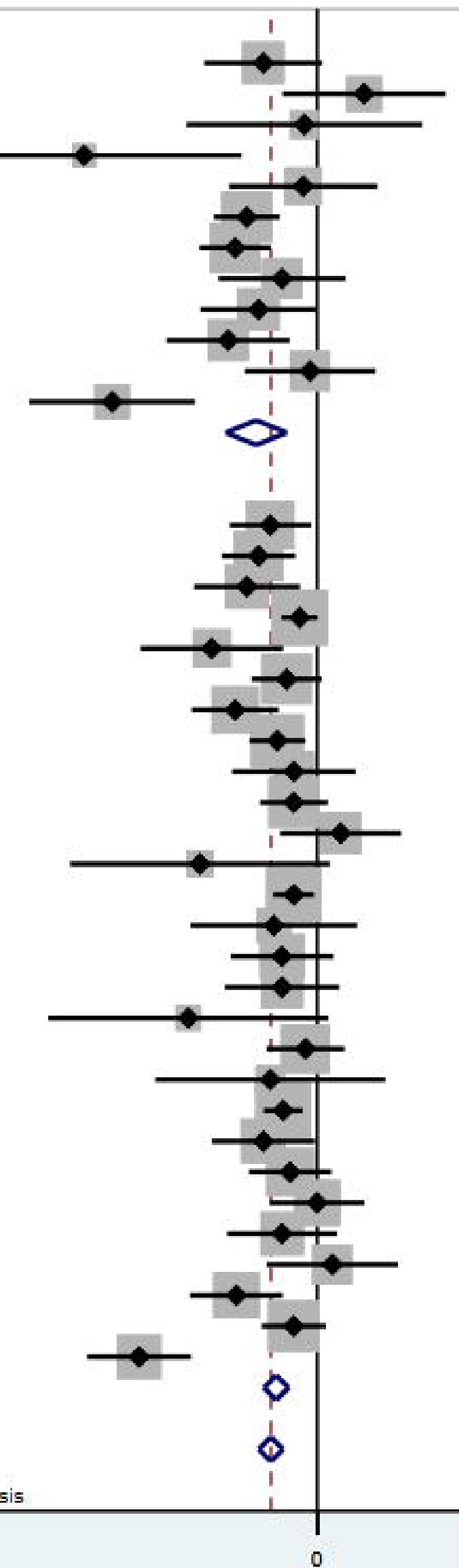

WMD (95\% CI)

\%
Weight

$0.46(-0.96,0.04)$

$-40(-0.30,1.10) \quad 1.52$

0.87

0.5

$-0.60(-0.88,-0.32) \quad 3.58$

- $30(-0.04,0.024)$

$-0.50(-0.99,-0.01) \quad 2.31$

2.10

$-0.06(-0.62,0.50) \quad 2.02$

$-1.75(-2.46,-1.04)$

$-0.40(-0.75,-0.05)$
$-0.50(-0.81,-0.19)$

$-0.60(-1.05,-0.15)$

$-0.15(-0.31,0.01)$

$-0.90(-1.51,-0.29)$
$-0.28(-0.56,0.04)$

$-0.70(-1.07,-0.33)$

$-0.20(-0.73,0.33)$

$-0.20(-0.48,0.09)$

$0.20(-0.32,0.72)$

$-0.20(-0.37,-0.03)$

$-0.30(-0.74,0.14)$

$-0.30(-0.79,0.10)$
$-1.10(-2.28,0.00)$

$-0.10(-0.43,0.23)$

$-0.28(-0.48,-0.12)$

$0.00(-0.40,0.40)$

$-0.30(-0.77,0.17)$

$0.13(-0.43,0.09)$

$-0.20(-0.48,0.08)$

$-1.52(-1.96,-1.08)$

$-0.39(-0.50,-0.29)$

1

Control group

FBG

Study

WMD (95\% Cl) Weigh

$-0.46(-0.96,0.04) \quad 2.26$

$0.40(-0.30,1.10)$

0.87 Goodarzi, M (2012)

$-1.99(-3.34,-0.64)$

$-0.12(-0.75,0.51)$
$-0.60(-0.88,-0.32)$

$-0.70(-1.00,-0.40)$

$-0.15(-0.31,0.01)$

$-0.13(-0.013,0.01)$

$-0.90(-1.51,-0.29)$
$-0.26(-0.56,0.04)$

$-0.70(-1.07,-0.33)$

$-0.34(-0.58,-0.10)$

$-0.20(-0.73,0.33)$

$-1.00(-2.11,0.11)$
$-0.20(-0.37,-0.03)$

$-0.30(-0.79,0.19)$

$-0.50(-0.99,-0.01)$

$-0.29(-0.48,-0.12)$

$-0.78(-1.29,-0.23)$
$-0.23(-0.58,0.12)$

$0.00(-0.40,0.40)$

$-0.30(-0.77,0.17)$
$-0.06(-0.02,0.50)$

$-0.06(-0.62,0.50)$
$-1.52(-1.96,-1.08)$

$-0.40(-0.52,-0.28)$

$-0.40(-0.75,-0.05)$

$-0.10(-0.43,0.23)$

$0.13(-0.43,0.69)$

$-0.69(-1.09,-0.29)$

$-0.20(-0.48,0.08)$
$-0.30(-0.47,-0.12)$

$-0.20(-0.48,0.09)$

$-.37(-1.08,0.34)$
$-1.10(-2.29,0.09)$

$-1.75(-2.48,-1.04)$

$\begin{array}{ll}-.46,-1.04) & 1.49 \\ -.58,-0.03) & 7.14\end{array}$

$-0.39(-0.50,-0.29) \quad 100.00$
Ramadas, A (2018)

Kim, H. S (2016)

Lim, S (2016)

Cho, J.H (2017)

Kleinman, N.J (2017)

Boaz, M (2009)

Zhou, P (2014)

Cho, J.H (2011)

Bujnowska.Fedak, Mm (2011)

Kempf, K (2017)

Moattari, M (2013)

Kim, S. I (2008)

Rossi, Mc (2013)

Overall (1-squared $=57.6 \%, p=0.003$ )

NOTE: Weights are from random effects analysis

-5.02
Intervention group
Fortmann, A. L (2017)
$-0.47(-1.37,0.43) \quad 8.30$

$0.50(-0.42,1.42) \quad 8.18$

$-0.70(-1.29,-0.11) \quad 10.89$

$-0.90(-1.79,-0.01) \quad 8.36$

$-0.24(-0.58,0.10) \quad 12.95$

$0.30(-1.03,1.63) \quad 5.57$

$-1.40(-2.64,-0.16) \quad 6.07$

$-2.39(-5.02,0.24) \quad 201$

$-0.96(-1.71,-0.21) \quad 9.57$

$-0.80(-2.13,0.53) \quad 5.50$

$-0.56(-2.26,1.14) \quad 4.01$

$-1.50(-2.42,-0.58) \quad 8.17$

$-0.31(-3.44,2.82) \quad 1.47$

$-1.46(-3.41,0.49) \quad 3.28$

$1.90(0.58,322)$

$-0.52(-0.93,-0.12) \quad 100.00$ 


\section{(A)}

$\mathrm{HbA} 1 \mathrm{c}$

Study
ID

Goodarzi, M(2012)
Yaron, (2019)

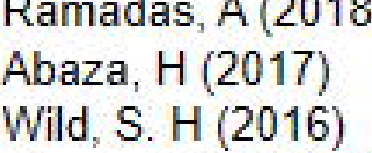

Durturk N $N$ (2019)
Sararyani $A$ (2018

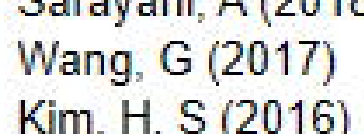

Kim, S (2016)

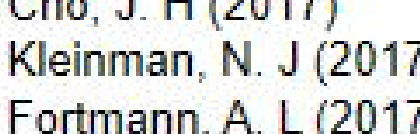

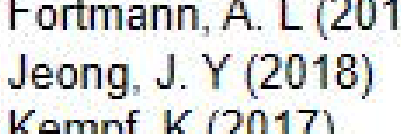

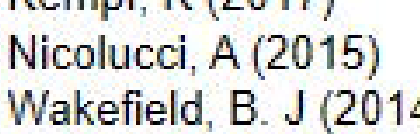

Wakefield, B. . (2014)

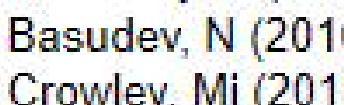

Odnoletkova, I (2016)
Baron, $J . S(2017)$

Benson, G.A (2019)
Boaz, M (2009)

Liou, J. K. (2014)
Rossi, M. C. E (2010)

Davis, R.M. (2010)
Shea, 5 (2009)

Kiman, M(2013)

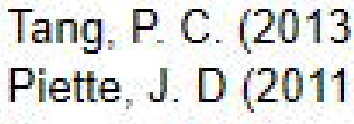

Cho, J. H(2011)
Bunowska-Fedak, Mm (2011)

Berndt, R-D (2014)
Charpentier, G (2011)

Moattari, $M(2013)$

Overall (I-squared $=50.5 \%, \mathrm{p}=0.000$

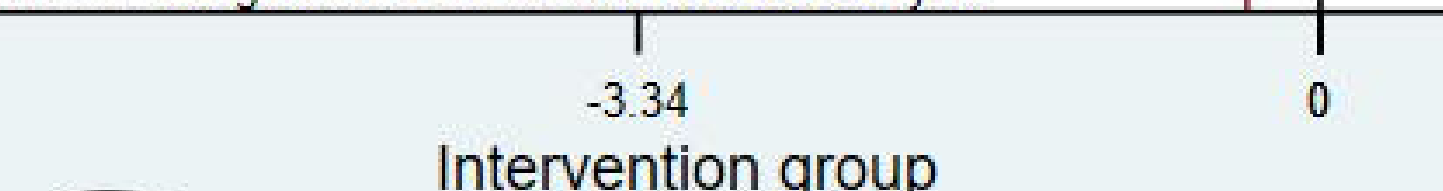

C

SBP

ID

Piette, J. D (2012) Bobrov, K (2016)

Kim, Y. N (2015)

McManus, R. J (2018)

Rifkin, D. E (2013)

Wild, S. H (2016)

Lee, $\mathrm{P}$ (2016)

Kim, J. Y (2016)

Kim, H. S (2016)

Lim, $S(2016)$

Cho, J. H (2017)

Fortmann, A. L (2017)

Kempf, K (2017)

Nicolucci, A (2015)

Crowley, Mj (2016)

Odnoletkova, I (2016)

Baron, J. S (2017)

Davis, R. M (2010)

Shea, S (2009)

Zhou, P (2014

Tang, $P(2013)$

Bujnowska-Fedak, Mm (2011)

Rossi, Mc (2013)

Margolis, K. L (2013)

Overall (I-squared $=60.1 \%, p=0.000$ )

NOTE: Weights are from random effects analysis

$$
\begin{gathered}
-15.6 \\
\text { Intervention group }
\end{gathered}
$$

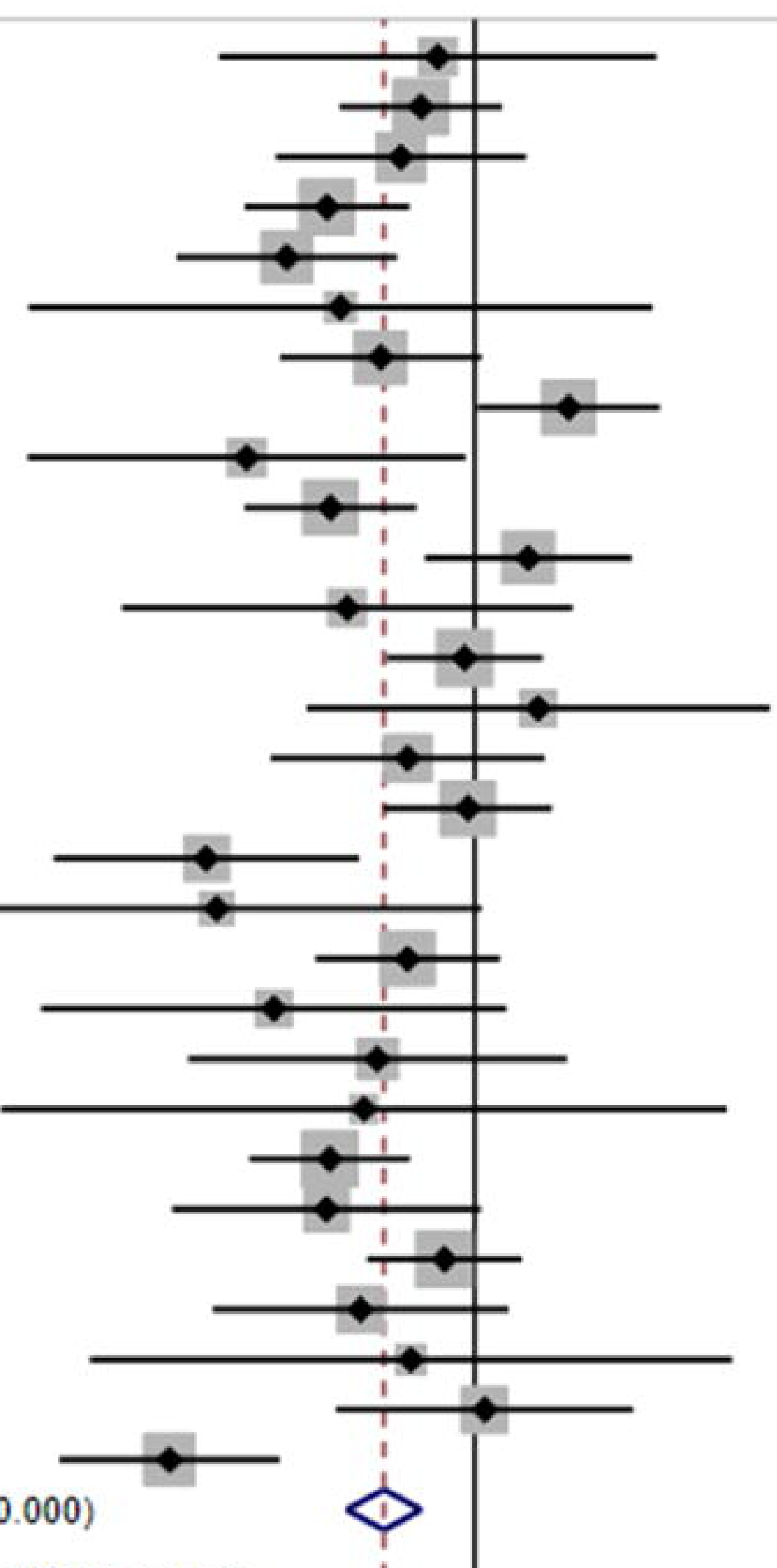

i

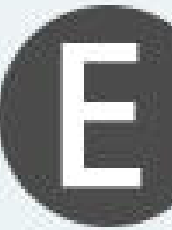

DBP

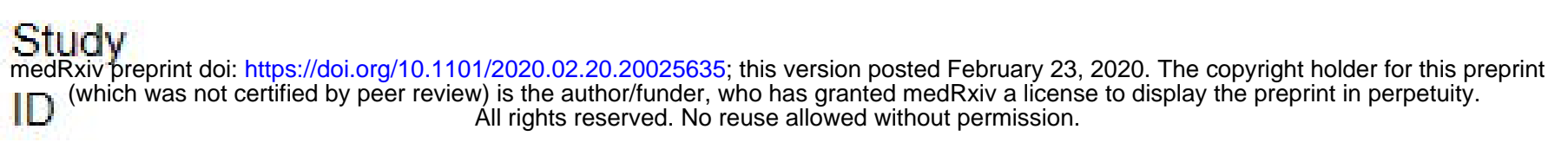

Kim, Y. N (2015)

McManus, R. J (2018)

McManus, R. J (2010)
Rifkin, D. E (2013)

Wild, S. H (2016)

Lee, $P(2016)$

Kim, J. Y (2016)

Kim, H. S (2016)

Lim, S (2016)

Cho, J. H (2017)

Fortmann, A. L (2017)

Nicolucci, A (2015)

Basudev, $\mathrm{N}(2016)$

Crowley, Mj (2016)

Odnoletkova, I (2016)

Baron, J. S (2017)

Davis, R. M (2010)

Davis, R. M (2010)

Zhou, P (2014)

Tang, P (2013)

Piette, J. D (2011)

Bujnowska-Fedak, Mm (2011)

Rossi, Mc (2013)

Margolis, K. L. (2013)
Overall (I-squared $=49.6 \%, p=0.002$ )
WMD (95\% CII) $\stackrel{\%}{\text { Weight }}$

FBG

WMD $(95 \% \mathrm{Cl}) \quad$ Weigh

Goodarzi, M (2012)

Ramadas, A (2018)

Kim, H. S (2016)

Cho, J. H (2017)

Kleinman, N. J (2017)

Fortmann, A. L (2017)

Boaz, M (2009)

Zhou, P (2014)

Cho, J. H (2011)

Bujnowska-Fedak, Mm (2011)

Kempf, K (2017)

Moattari, M (2013)

Kim, S. I (2008)

Overall (I-squared $=36.6 \%, p=0.083$ )

$-0.20(-0.48,0.08)$
-0.967

Control group

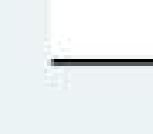

$-0.47(-1.37,0.43) \quad 5.95$

$0.50(-0.42,1.42)$

$-0.70(-1.29,-0.11) \quad 13.75$

$-0.90(-1.79,-0.01) \quad 6.06$

$-0.24(-0.58,0.10)$

$0.30(-1.03,1.63) \quad 2.74$

3.18

$-0.80(-2.13,0.53) \quad 2.75$

$-0.56(-2.26,1.14)$

$-1.50(-2.42,-0.58) \quad 5.74$

$-0.31(-3.44,2.82) \quad 0.49$

$-1.46(-3.41,0.49) \quad 1.28$

$-0.52(-0.74,-0.30) \quad 100.00$

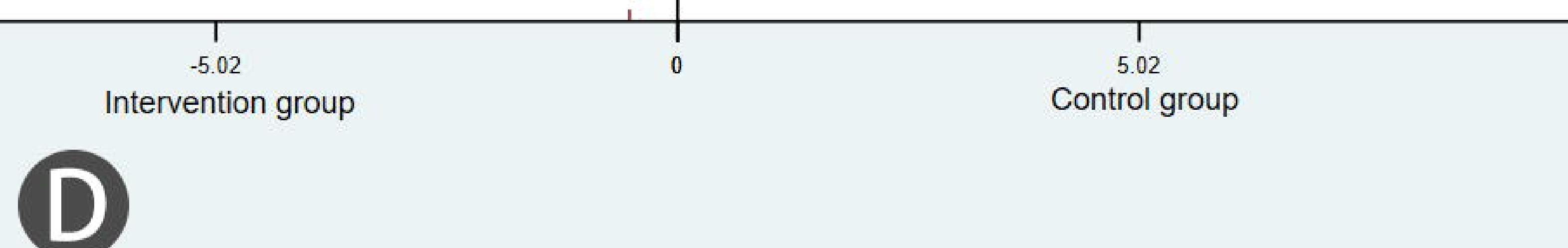

SBP

WMD $(95 \% \mathrm{Cl}) \quad$ Weight

Study

$-1.10(-7.62,5.42) \quad 2.05$

$-1.60(-4.03,0.83) \quad 5.10$

$-2.20(-5.93,1.53) \quad 3.84$

$-4.40(-6.86,-1.94) \quad 5.06$

$-4.00(-13.30,5.30) \quad 1.1$

$-2.80(-5.81,0.21) \quad 4.52$

$2.80(0.07,5.53) \quad 4.79$

$-6.80(-13.32,-0.28) \quad 2.05$

$-4.30(-6.87,-1.73) \quad 4.95$

$1.60(-1.48,4.68) \quad 4.44$

$\begin{array}{cc}-3.80(-10.52,2.92) & 1.96 \\ -0.30(-2.63,2.03) & 5.19\end{array}$

$\begin{array}{cc}-0.30(-2.63,2.03) & 5.19 \\ 1.90(-5.01 .8 .81) & 1.89\end{array}$

$\begin{array}{ll}1.90(-5.01,8.81) & 1.89 \\ -200(-6.10 .2 .10) & 3.53\end{array}$

$\begin{array}{rr}-2.00(-6.10,2.10) & 3.53 \\ -0.20(-2.71,2.31) & 5.02\end{array}$

$\begin{array}{cc}-0.20(-2.71,2.31) & 5.02 \\ -8.00(-12.55,-3.45) & 3.18\end{array}$

$\begin{array}{ll}-8.00(-12.55,-3.45) & 3.18 \\ -7.70(-15.61,0.21) & 1.54\end{array}$

$-2.00(-4.76,0.76) \quad 4.76$

$-5.99(-12.93,0.95) \quad 1.87$

$\begin{array}{ll}-2.90(-8.55,2.75) & 2.48 \\ -3.30(-14.11,7.51) & 0.92\end{array}$

$\begin{array}{rr}-3.30(-14.11,7.51) & 0.92 \\ -4.32(-6.72,-1.92) & 5.13\end{array}$

$-4.42(-9.02,0.18) \quad 3.14$

$-4.42(-9.02,0.18)$
$-0.90(-3.20,1.40)$
5.22

$-3.40(-7.81,1.01) \quad 3.28$

$-1.90(-11.47,7.67) \quad 1.14$

$-9.10(-12.39,-5.81) \quad 4.25$

$271(-3.82,-1.59) \quad 100.00$

15.6

Control group

ID

Piette, J. D (2012)

Bobrow, K (2016)

Kim, Y. N (2015)

McManus, R.J J (2018)
McManus, R.J (2010)

McManus, R. J (2010)
Rifkin, D. E (2013)

Wild, S. H (2016)

Lee, $P(2016)$

Kim, J. Y (2016)

McKinstry, B (2013)

Kim, H. S (2016)

Lim, S (2016)

Cho, J. H (2017)

Fortmann, A. L (2017)

Kempf, $\mathrm{K}$ (2017)

Nicolucci, A (2015)

Basudev, N (2016)

Crowley, Mj (2016)

Odnoletkova, I (2016)

Baron, J. S (2017)

Liou, J. K (2014)

Davis, R. M (2010)

Shea, S (2009)

Zhou, $P$ (2014)

Piette, J. D (2011)

Bujnowska-Fedak, Mm (2011)

Rossi, Mc (2013)

Overall (I-squared $=49.6 \%, p=0.002$ )

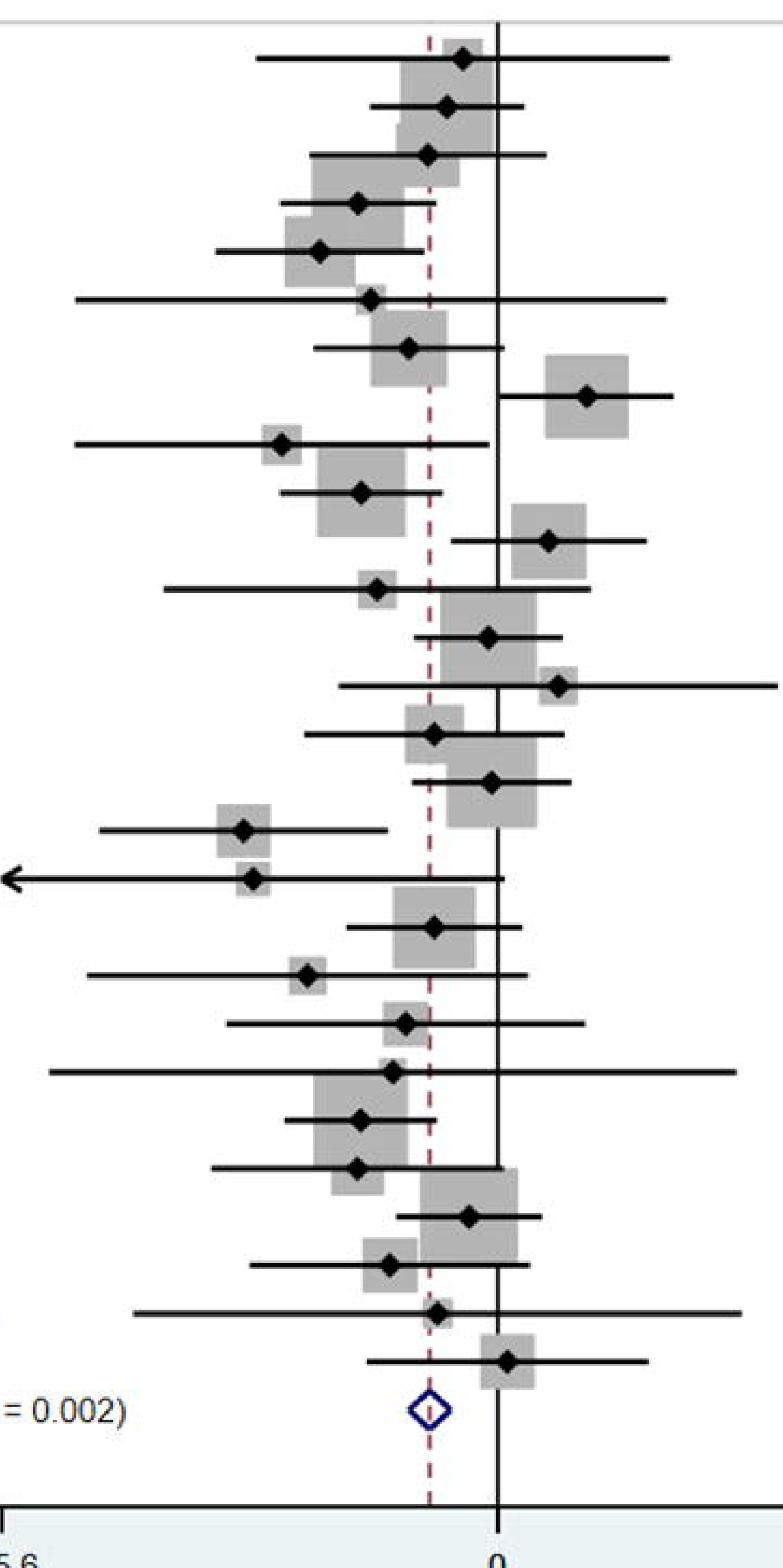

$-15.6$

Intervention group

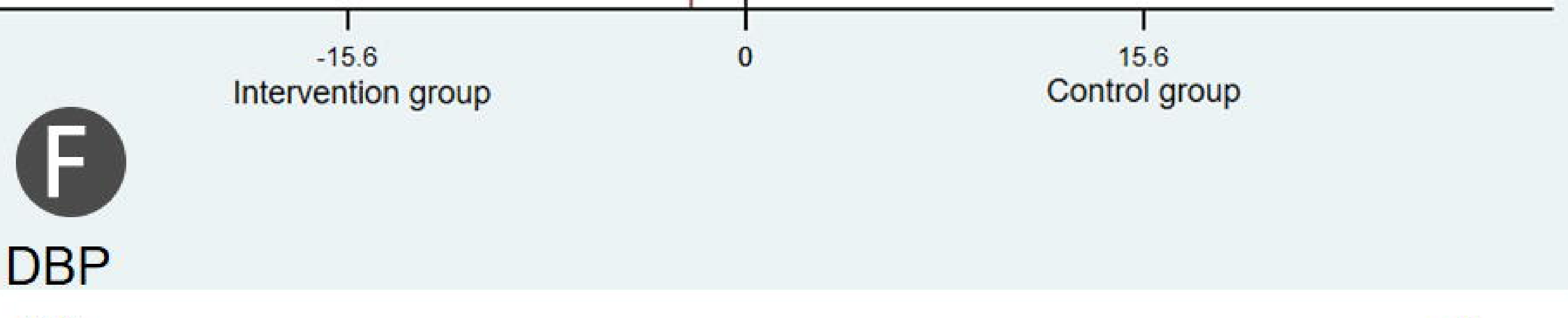

Study

Kim, Y. N (2015)

McManus, R. J (2018)

McManus, R. J (2010)

Rifkin, D. E (2013)

Wild, S. H (2016)

Lee, $\mathrm{P}(2016)$

Kim, J. Y (2016)

McKinstry, B (2013)

Kim, H. S (2016)

Lim, S (2016)

Fortmann, A. L (2017)

Kempf, $K$ (2017)

Nicolucci, A (2015)

Basudev, N (2016)

Crowley, Mj (2016)

Odnoletkova, I (2016)

Baron, J. S (2017)

Liou, J. K (2014)

Davis, R. M (2010)

Shea, S (2009)

Zhou, P (2014)

Tang, P (2013)

Piette, J. D (2011)

Bujnowska-Fedak, Mm (2011)

Rossi, Mc (2013)

Overall (I-squared $=42.7 \%, p=0.012$ )

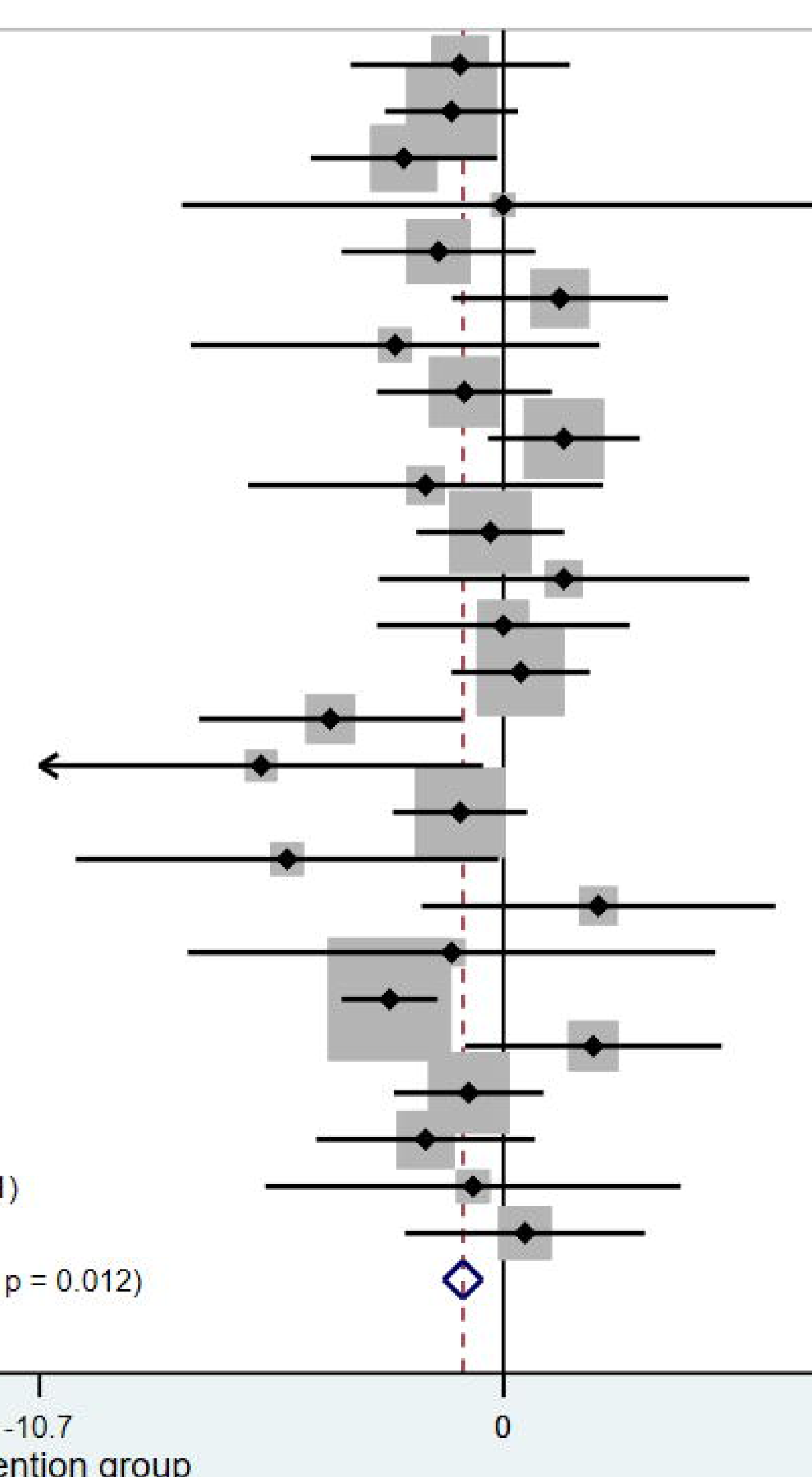

$-1.00(-3.53,1.53) \quad 3.10$

$-1.20(-2.74,0.34) \quad 8.40$

$-2.30(-4.46,-0.14) \quad 4.27$

$0.00(-7.43,7.43) \quad 0.36$

$-1.50(-3.74,0.74) \quad 3.95$

$1.31(-1.19,3.81) \quad 3.19$

$\begin{array}{ll}-2.50(-7.23,2.23) & 0.89 \\ -0.90(-2.92,1.12) & 4.85\end{array}$

$1.40(-0.36,3.16) \quad 6.44$

$-0.30(-2.00,1.40) \quad 6.85$

$1.40(-2.88,5.68) \quad 1.08$

$0.00(-2.92,2.92) \quad 2.33$

$0.40(-120,200) \quad 775$

$-4.00(-7.04,0.96) \quad 2.15$

$560(-1073,0.47) \quad 0.76$

(1.00

$-500(-089,011) \quad 083$

$20(-1.89,6.29)$

$-120(-7.30,4.90) \quad 0.53$

$-2.63(-3.74,-1.52) \quad 16.17$

$2.08(-0.88,5.04) \quad 2.26$

$-0.80(-2.53,0.93) \quad 6.65$

$-1.80(-4.33,0.73) \quad 3.11$

$0.50(-2.27,3.27) \quad 2.59$

$-0.93(-1.38,-0.49) \quad 100.00$
$-1.80(-5.90,2.30) \quad 1.18$

$-0.70(-5.50,4.10) \quad 0.86$ 
Piette, J. D (2012) Kim, Y N (2015) McManus, R J (2018) McManus, R J (2010) Rifkin, D. E (2013) Wid, S. H (2016) Lee, P (2016) Kim, J. Y (2016) McKinstry, B (2013) Kim, H. S (2016) Lim, S (2016)

Cho. J. H (2017)

Fortmann, A L (2017) Kempt, K (2017)

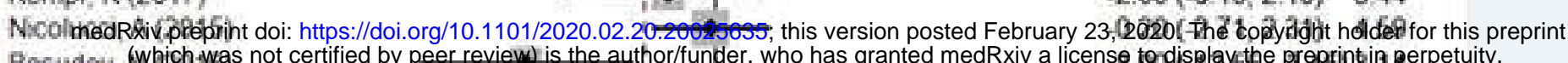
Basudev, Nhichive Crowley. Mi (2016)
Odnoletkova, I (2016 Baron, J S (2017) LHou, J. K (2014) Davis, R M (2010) Shea, S (2009) Zhou, $P(2014)$ Pang, $P(2013)$ Bujnowska.Fedak, Mm (2011) Rossi, Mc (2013) Margolis, K. L. (2013) Green. B B (2008)

Cratl (1-squared NOTE Weights are from random effects analysis

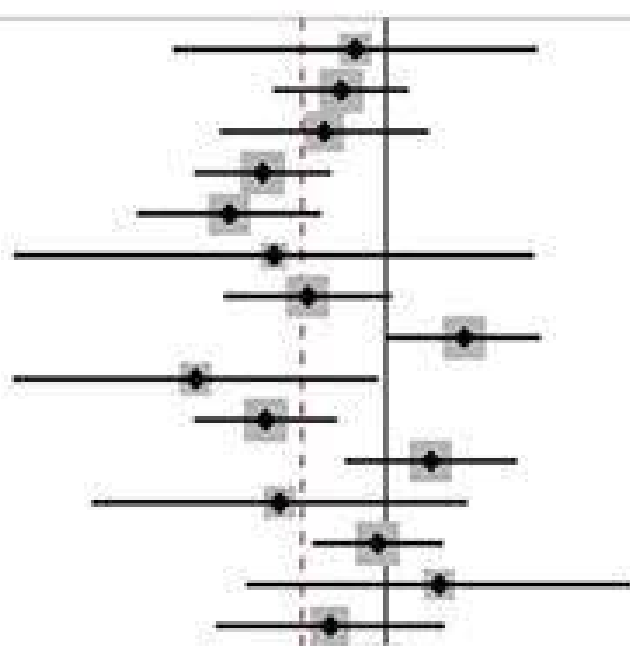

$\begin{array}{ll}-1.10(-7.62,5.42) & 2.13 \\ -1.13 & -403\end{array}$ $-1.60(-4.03,0.83) \quad 4.65$ $-4.40(-686,-1.94) 463$ $-5.60(-8.89,-2.31) 401$ $4.00(-13.30,5.30) 1.29$ $2.80(-5.81,0.21) \quad 4.22$ $2.80(0.07,5.53) \quad 4.43$ $6.80(-13.32,-0.28) 2.12$ $4.30(-6.87,-1.73) 4.55$ $1.60(-1.48,4.68) \quad 4.16$ $3.80(-10,52,2.92) 205$ $-0.30(-263,203) \quad 4.72$ $1.90(-5.01,8.81) \quad 1.97$

$70(-15.61,0.21) 1.64$ $2.00(-4.76,0.76) \quad 4.40$ $5.99(-1293,0.95) 1.96$ $2.90(-8.55,2.75)$ 2.52 $4.30(-1411,7.51) 1.01$ $4.42(-902,0.18) \quad 3.11$ $0.42(.92,0.18) 3.11$ $340(781,101) \quad 323$ $-190(-11.47,7.67) 123$ $30(-4.13,4.73) \quad 321$ $910(-1239,-581) 401$ $8.40(-11.05,-5.75) 4.49$ $299(-4.19,-1.80) 10000$
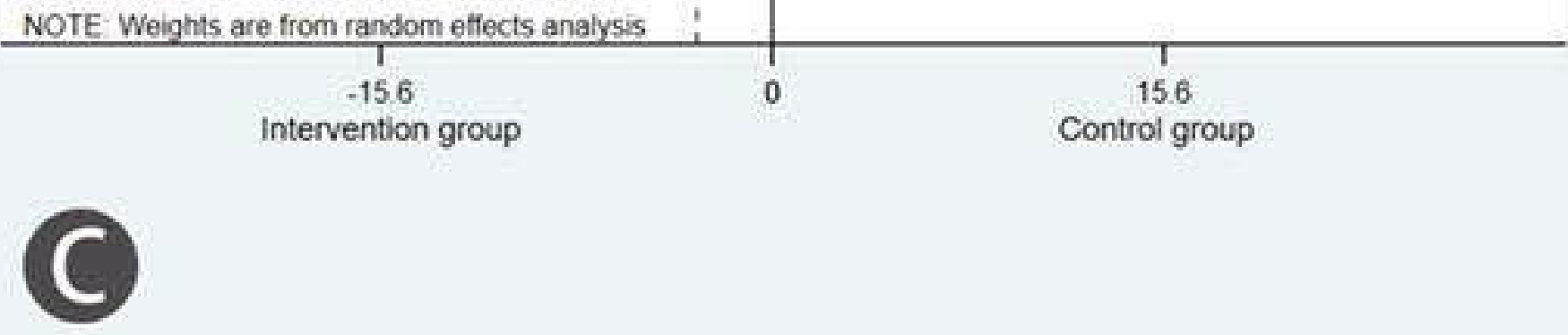

SBP

Stud

mHasth aloon

Puete. J. D (2012)

Bobrow, K (2016)

Leo. $P(2016)$

MeManus, $R \cdot J$ (2018)

MeManus, R.J(2010)

Rimin D E (2013)

Subtotal (1-squated $=756 \%, q=0$ cot)

Combined intervertion

KMm. Y N (2015)

Margolh, KL (2013)

Green B. B (2008)

$\mathrm{Km} . \mathrm{Y} Y(2016)$

Mckinstry, 8 (2013)

Subtotal (1-squned $=67.2 \%, p=0.016)$.

Oretal (M-squared $=20.3 \%, p=0.000$

NOTE Weights are from tansom estects analysis

Intervention group .133

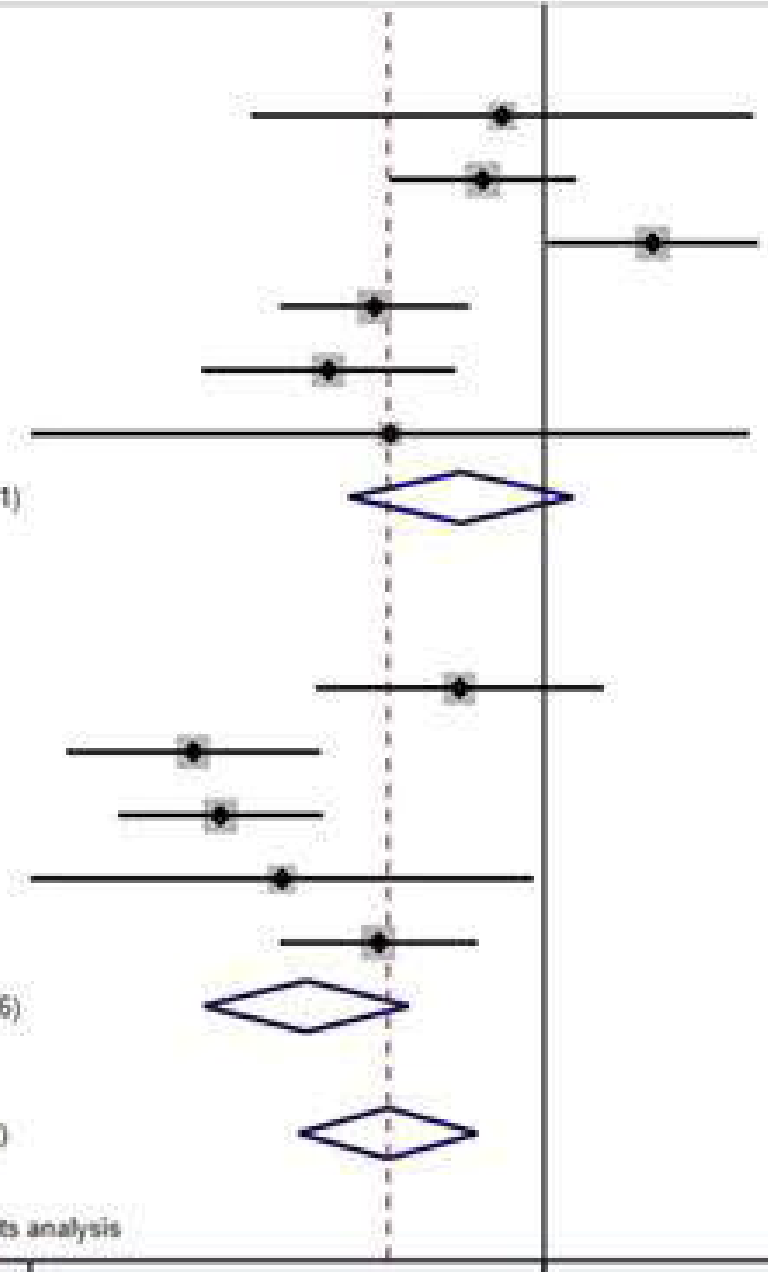

nroup

\section{Mo (95: C)}

$-1.10(-7.62 .5 .42)$

$-160(-403,0.83)$

$280(007.553)$

$-4.40(-686,-1.94)$

$-560(-8.89,231)$

$-400(-1330,5.30)$

$-2.16(-5.07,0.75)$

$-220(-593,1.53)$

$-9.10(-1239,-581)$

$840(-1105,-5.75)$

$-680(-1332,-028)$

$430\left(-687_{i}-1.73\right)$

$-6.17(-8.83-350)$

$-4.05(-6.37,-1.74)$

WMD (95\% Cl)

seveloping country

Piette, J. D (2012)

Bobrow, K (2016)

Lee, $P(2016)$

subtoctal (1-squared $=65.2 \%, p=0.056$ )

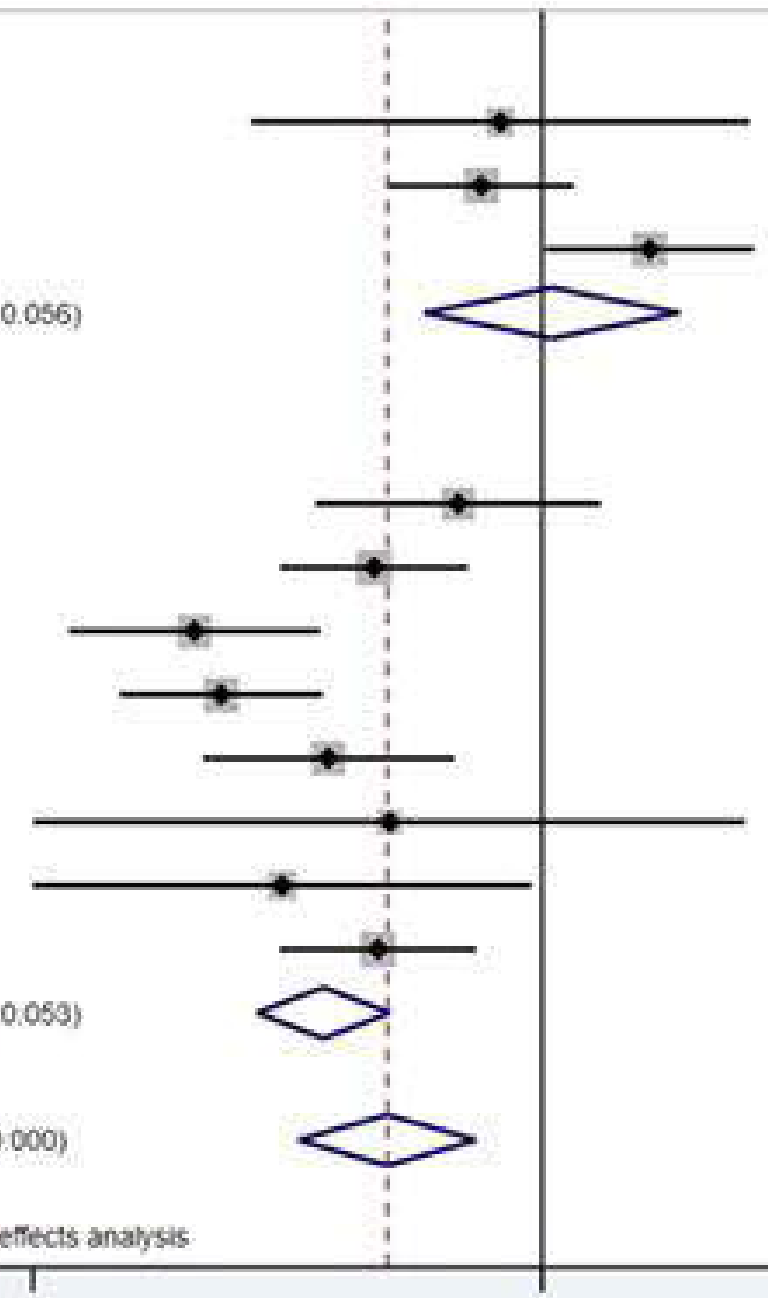

$1.10(-7.62 .5 .42)$

severoped countey

$\mathrm{Km}, \mathrm{Y}, \mathrm{N}(2015)$

Mchanus, R J (2018)

Margolis, K L (2013)

Green, $B . B$, (2008)

McManus, R. J(2010)

Rifion O. E (2013)

$\mathrm{Kim}, \mathrm{J}, \mathrm{Y}(2016)$

Mckinstry. 8 (2013)

Sublotat $(1-$ squared $=49.7 \%$. $p=0.053$

Overall (1-squared $=80.3 \%, p=0.000)$

intervention group

$160(403,083)$

$280(0.07,5.53)$

$0.25(-3.10,3.59)$

278

$-220(-5.93,1.53) \quad 9.41$

$4.40(-6.86,-1.94) \quad 1092$

$.9 .10(-12.39,-5.81) \quad 996$

$8.40(-11.05,-5.75) \quad 1071$

$-560(-8.89 .231) \quad 9.95$

$-400(-1330,530)$

$-6.80(-13.32,-0.28) \quad 6.26$

$-4.30(-687,-173) \quad 1050$

$-5.72(-7.46,-399)-72.15$

$-4.05(-6.37,-1.74) \quad 100.00$

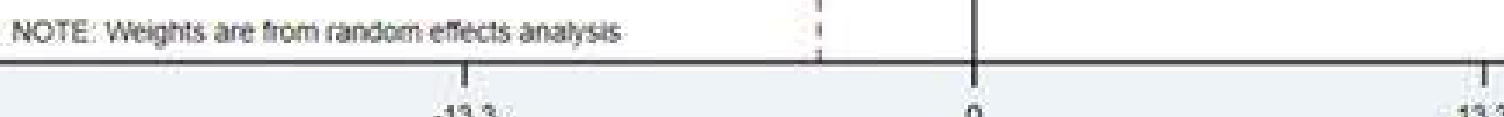$$
\text { Controlgroup }
$$

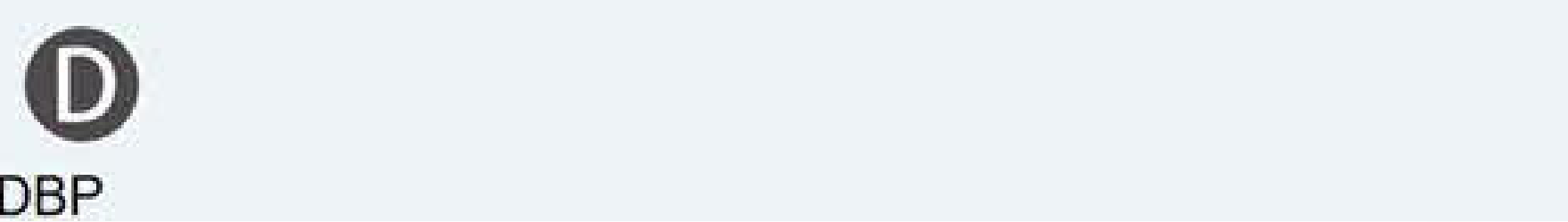

Study
ID

